\author{
ارزيابى عملكرد الخوريتم كلونى زنبور عسل در تحليل تناوب سيلاب \\ ستار جاوشى" و كورش شيرانى'

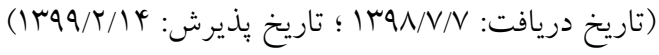

جكيده

انتخاب تابع توزيع مناسب و تخمين پارامترهاى آن دو گام اساسى در برآورد دقيق تناوب سيلاب است. در اين مقاله براى بهبـود تخمــين

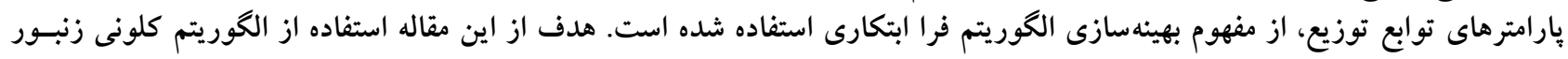

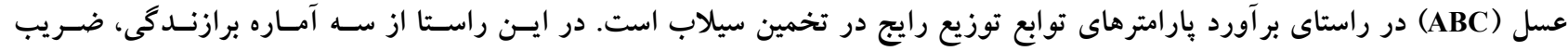

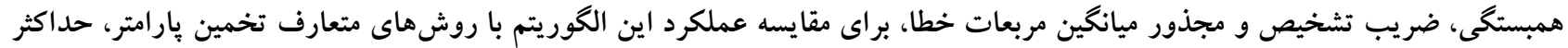

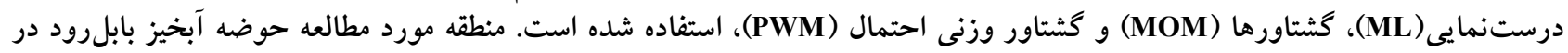

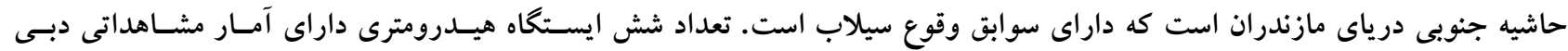

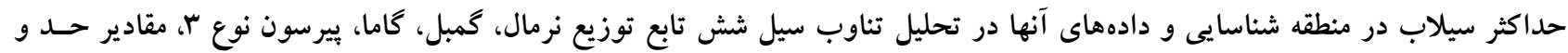

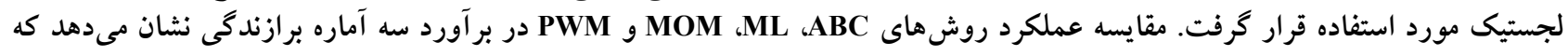

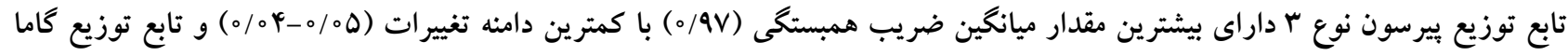

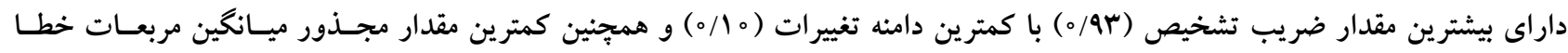

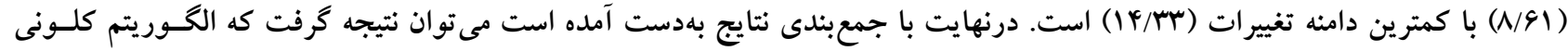

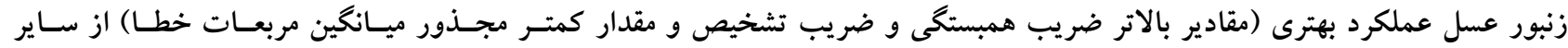

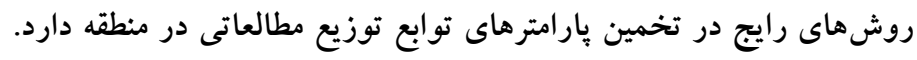

وازههاى كليدى: تناوب سيل، تخمين پارامتر، الخوريتم فرا ابتكارى، الخوريتم كلونى زنبور عسل

ا. بخش تحقيقات حفاظت خاك و آبخيزدارى، مركز تحقيقات و آموزش كشاورزى و منابع طبيعى استان اصفهان، سـازمان تحقيقـات، آمـوزش و ترويج كشاورزى، اصفهان، ايران

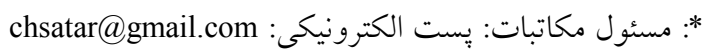


بيشبينى آن در آينده مفيد باشد. در سالهـاى اخيـر استفاده از

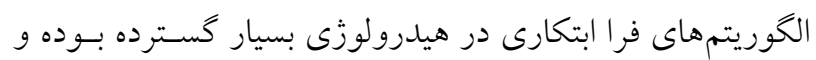

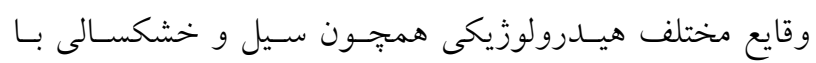

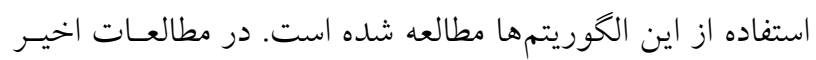

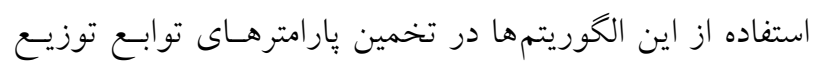

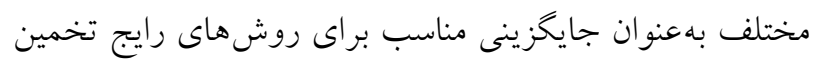

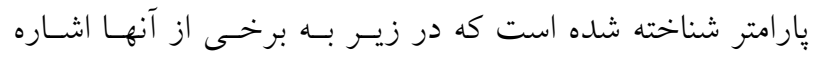
مىشود. شين و همكاران (YY) بهمنظور توصيف خصوصيات آمـارى

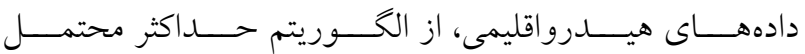
براى تخمسين (Expectation Maximization Algorithm, EM) بارامترهـاى تـابع توزيـع نرمـال مخلـوط (Mixture Normal)

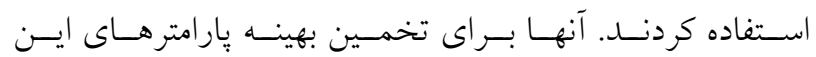

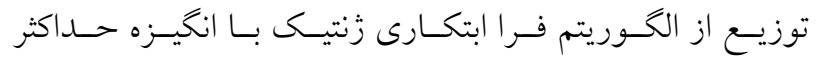

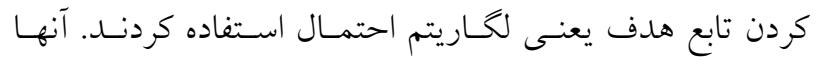

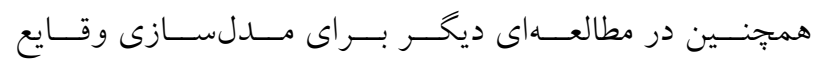

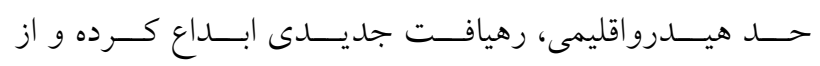

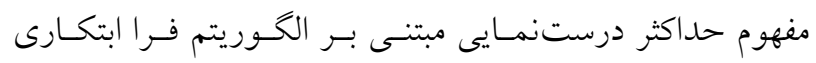
بــــاى تخمــين (Meta-heuristic Maximum Likelihood)

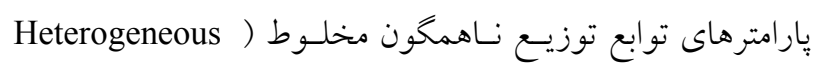

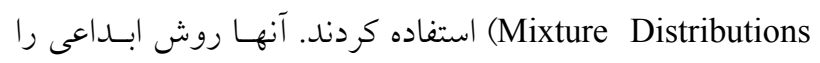
براى مطالعه بارش هاى حداكثر كره جنوبى بهكار كرفتند و جنين

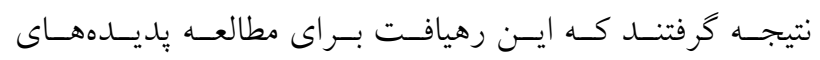

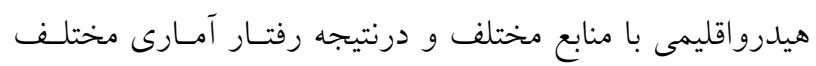

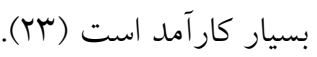
از ديخر كاربردهاى الكوريتمهاى فرا ابتكـارى در مطالعـات التهات

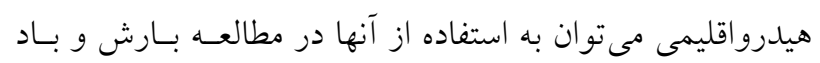

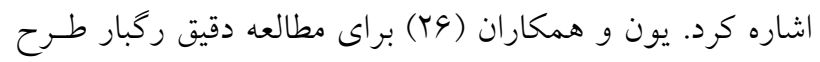

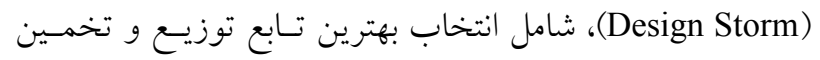

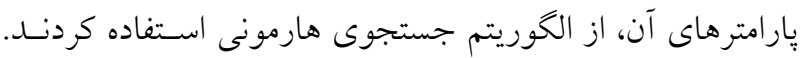

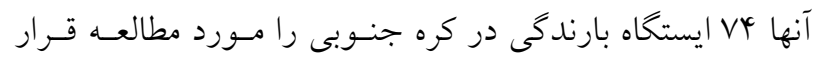

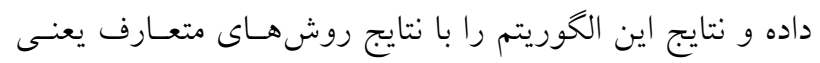

وقوع سـيلاب بـهـ لحـاظ عواقـب آن همجــون تلفـات جـانى و

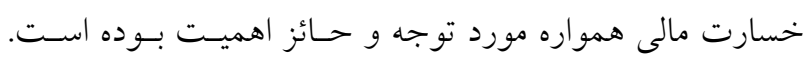

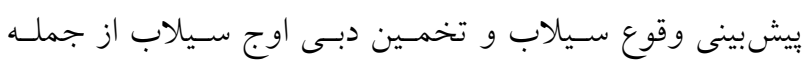

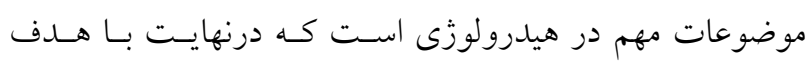

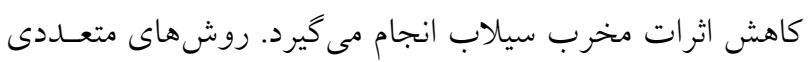

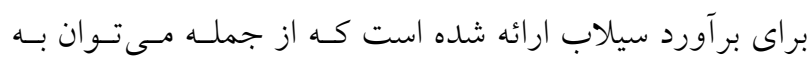

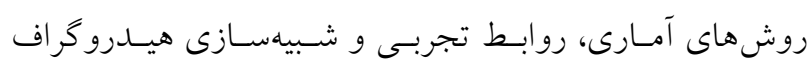

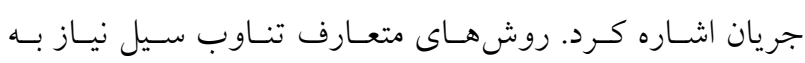

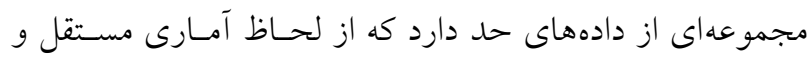

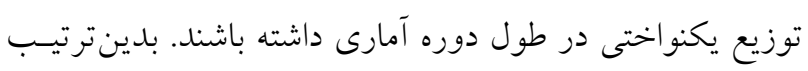

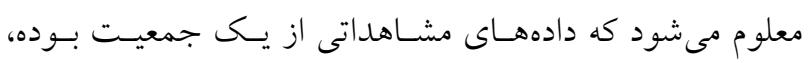

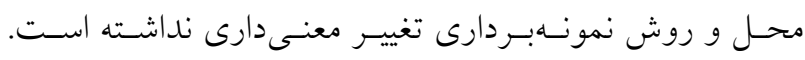

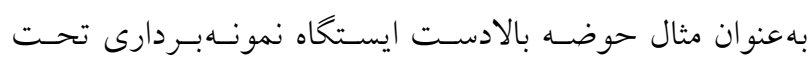

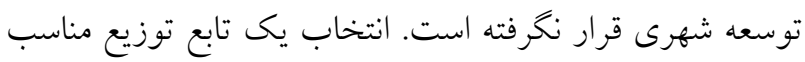

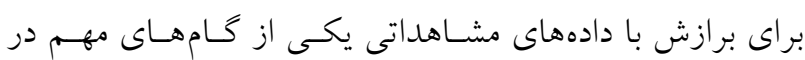

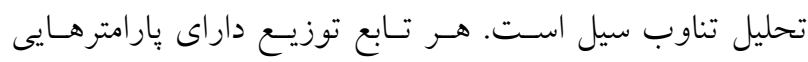

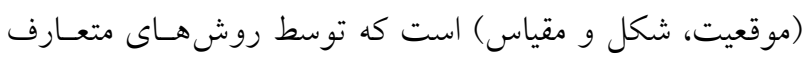

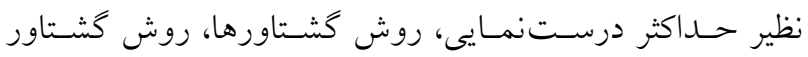

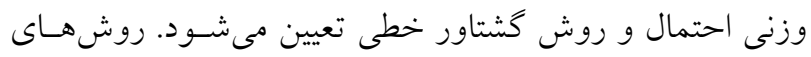

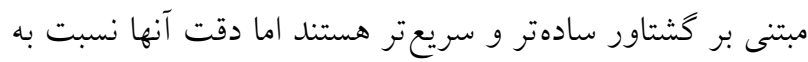
روش حداكثر درستنمايى كمتر است. در مقابل روش حسداكثر

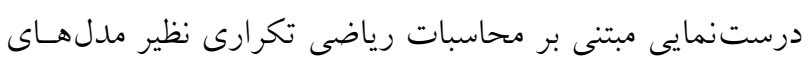

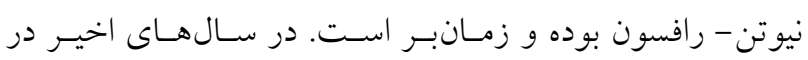

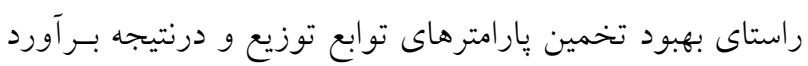

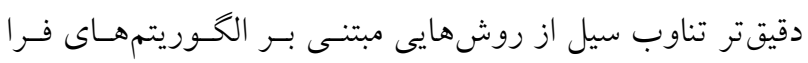

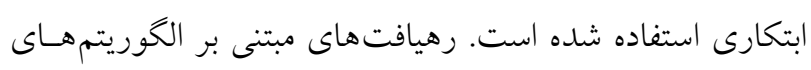

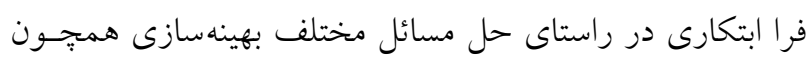

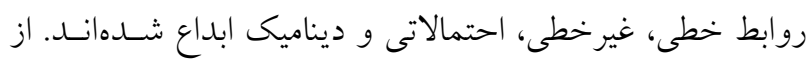

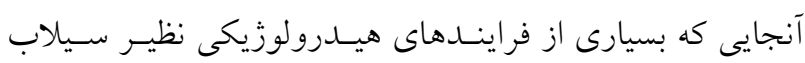

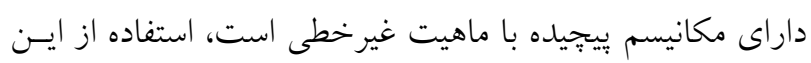

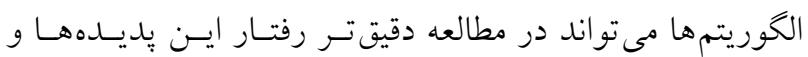


مشاهداتى باد، روش كشتاورها مناسـبتـــين روش تخمـين و

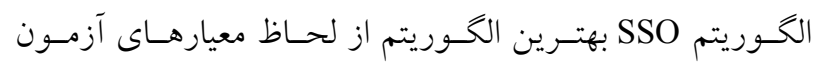

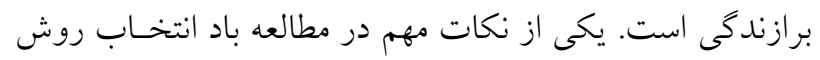

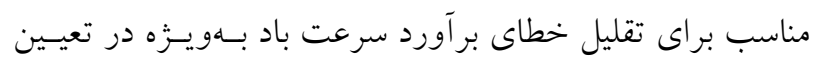

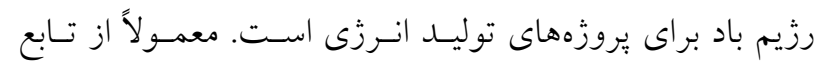

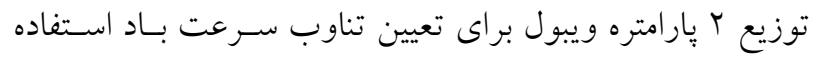

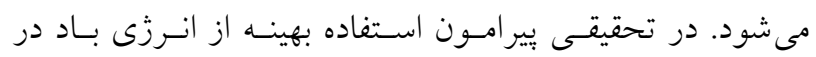

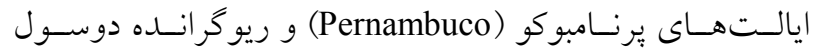

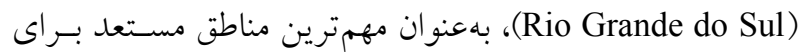

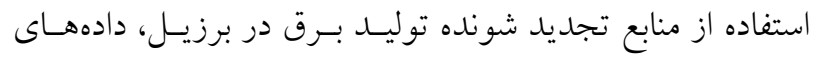

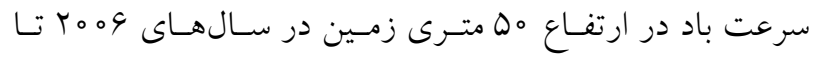

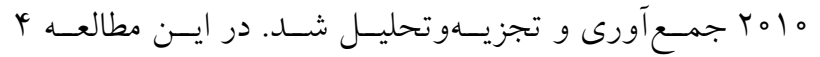
الكوريتم فرا ابتكارى جستجوى هارمونى، الكوريتم بهينهسـازى كوكـ (Cuckoo Search Optimization, CSO)، بهينهســازى ازدحام ذرات و كلونى مورجهه بهكار كرفته شد و نتسايج حاصل

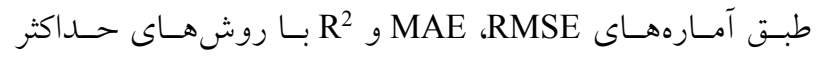
درستنمايى، گشتاورها، روابط تجربسى و روش انـرزى معـادل

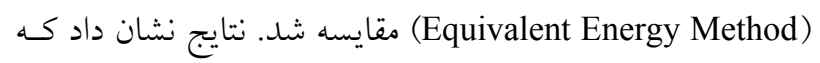

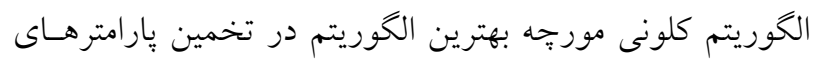

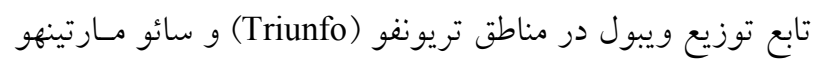

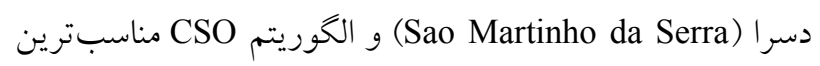

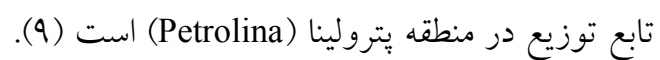

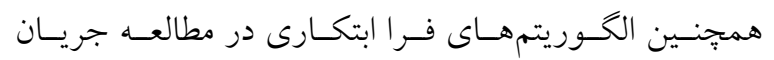
رودخانه، رواناب و سيل مورد استفاده قرار گرفته است. لنخـات

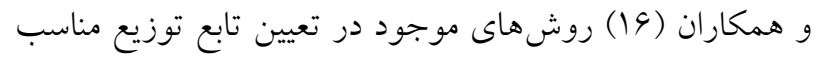
براى تخمين دادههاى جريان حداكث، حداقل و ميانگين را مرور كرده و سبس عملكرد شش تابع توزيع را مقايسه و جهار آزمون برازش، ارزيابى و انتخاب را به تصوير كشسيدند. روش حسداكثر

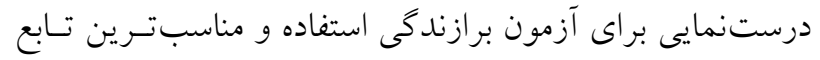

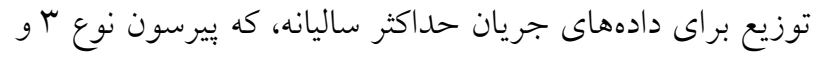
لو گ نرمال است، انتخاب شد. توابع توزيع ويبول، مقادير حد و و كامبل بهترين تابع توزيع براى تخمسين جريسان حسداقل سـالانه
حداكثر درسـتنمـايى، گشـتاورها و گشـتاور وزنسى احتمـال و

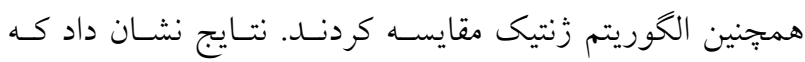

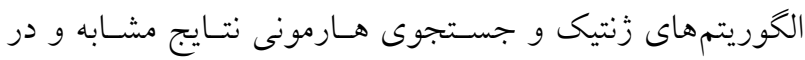
عين حال دقيقترى از روشهاى متعارف ارائه مىدهد.

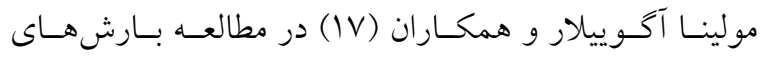

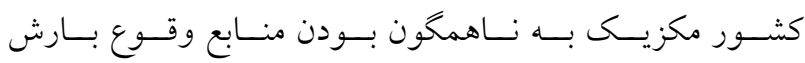

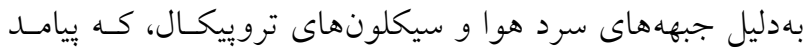

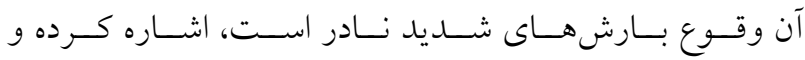

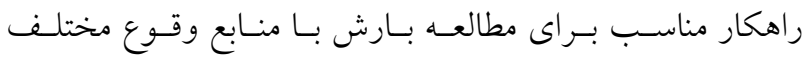

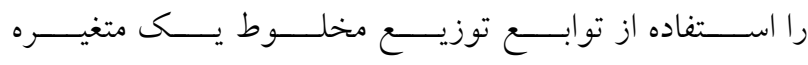
(Univariate Mixed Probability Distribution Functions)

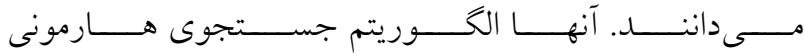

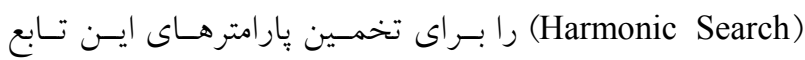

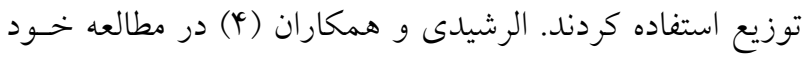
به اهميت بر آورد دقيق سرعت باد براى بـروزههــاى استحصـال

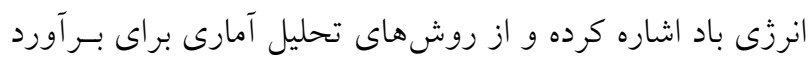

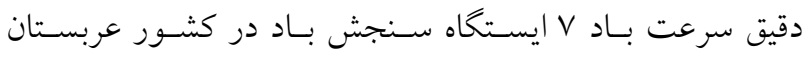

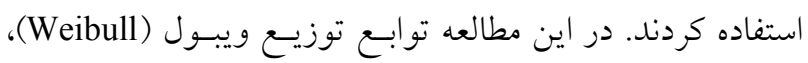

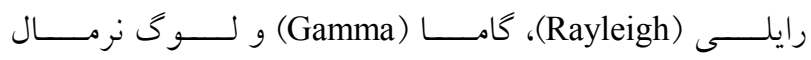

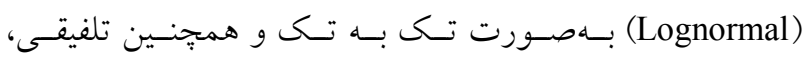

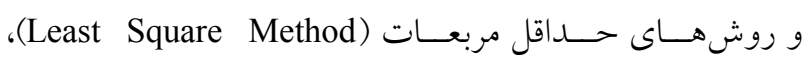

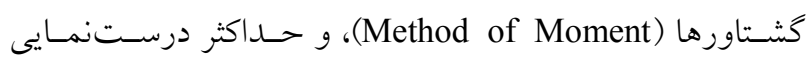
بــاى بــرآورد (Maximum Likelihood Estimation Method)

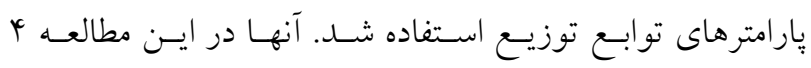

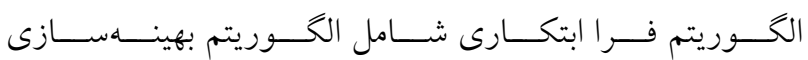
عنكبـوت (Social Spider Optimization , SSO)، الخـوريتم

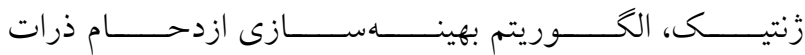
(Particle Swarm Optimization, PSO) كايوت (Coyote Optimization Algorithm, COA) را بـراى بهينهسازى فرايند تخمسين يارامترهـاى توابـع توزيـع منطبـق بـا.

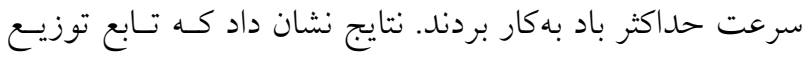

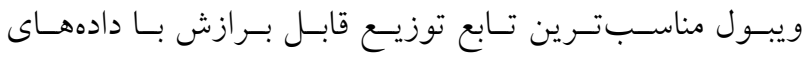


الخــوريتم زنتيـك و الحــوريتم تكـاملى تفاضـلى ( Differential

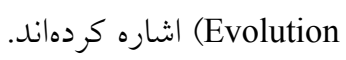
در منطقه مورد مطالعه مطالعـات زيـادى در زمينـه سـيلاب انجام گرفته كه عمدتاً از روش هاى كلاسيك استفاده شده است. از جمله مىتوان به مقالات عبدالحى (1)، آهنى و همكاران (Y)، (1)،

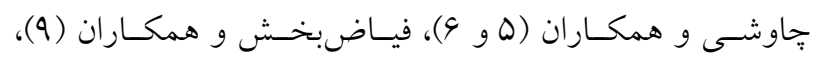
رستمى كـامرود و همكـاران (11)، ثقفيـان و فرازجــ (19)، و شعبانلو و همكاران (Yo) اشاره كرد.

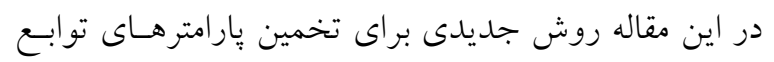

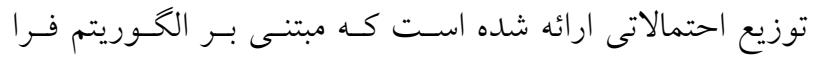

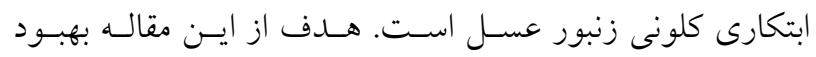

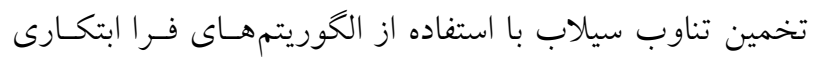

\section{مواد و روشها

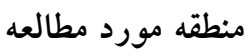

منطقه مورد مطالعه يكى ازحوضه هاى آبخيـز دريـاى مازنـــران

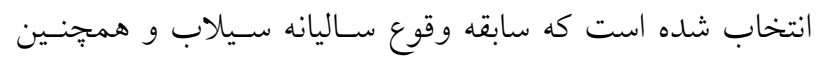

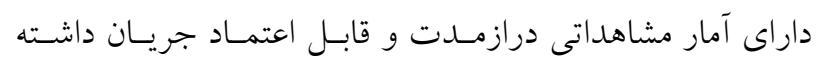

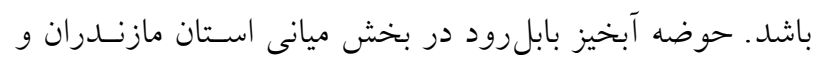

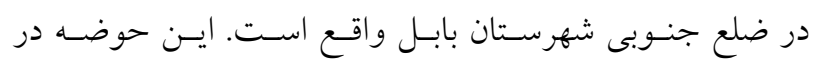
حدفاصل '9 هول شرقى واقع است. اين حوضه از شمال بـهـ شـهر

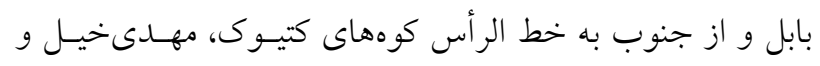
كرليبن از شرق به كوههـاى يورخسانى و از غـرب بـهـ كـوه دزو

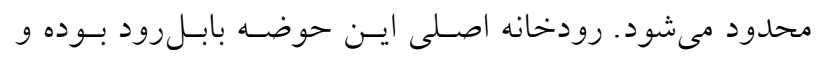

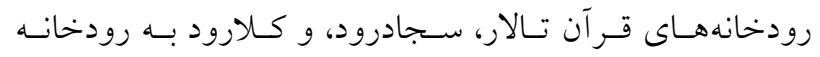

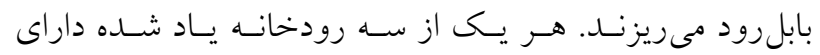

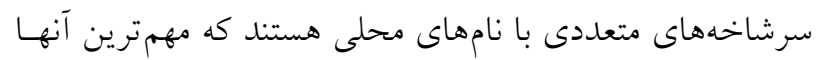

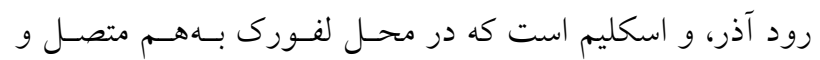

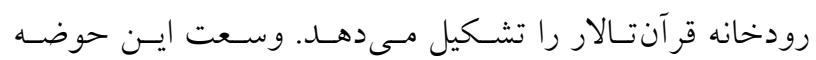

رودخانه تانا (Tana River) در كشور كنيا تعيسين شـد، درحسالى تئ كه توابع توزيع مقادير حد و لوى نرمال مناسبترين تابع توزيع براى تخمين جريان ميانكين سالانه اين رودخانه است.

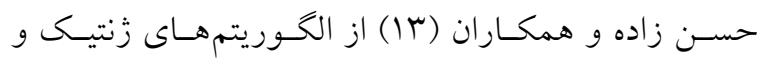
كلونى مورجهه در تخمسين بارامترهـاى توابـع توزيـع اسـتفاده

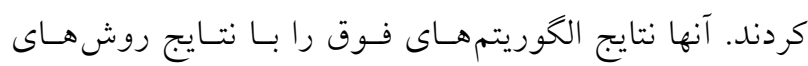

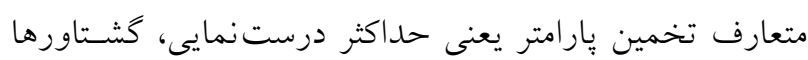

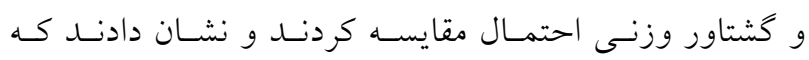

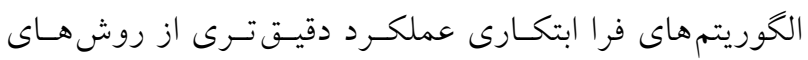
متعارف دارد. - ماري طلعت اهرى و همكاران (TQ) نسخه جداريــى از الحــوريتم

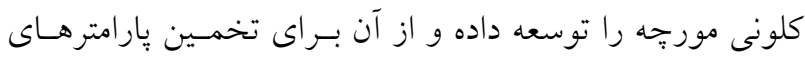

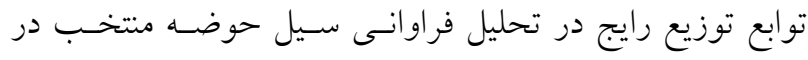

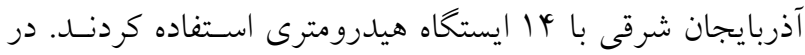

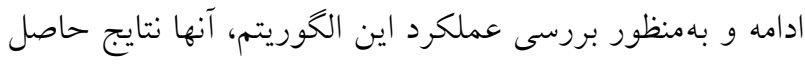

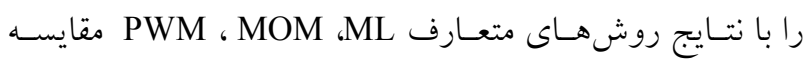

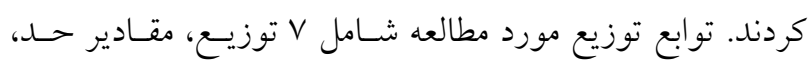

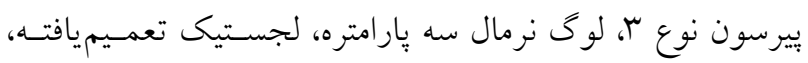

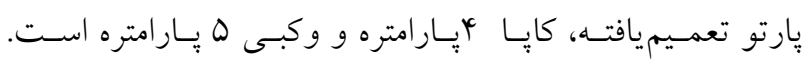

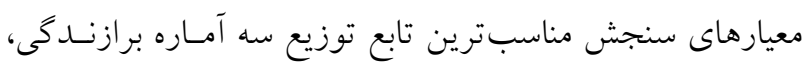

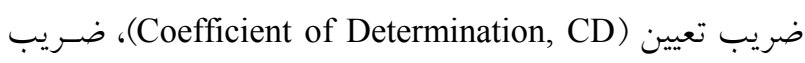
عملكــرد (Coefficient of Efficient, CE) و جـــر ميـانخين مربعات خطا (Root Mean Square Error, RMSE) است. نتايج بيانكر عملكرد قابل قبول ايسن الخــوريتم در تخمسين بارامترهـاى

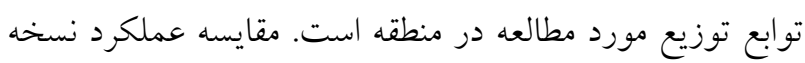

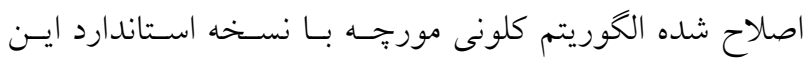

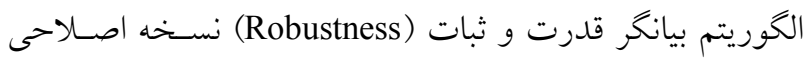

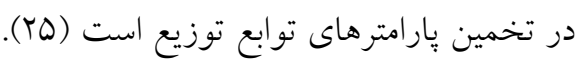

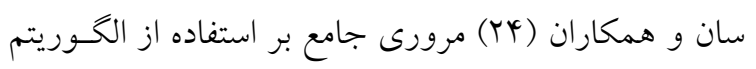
هاى فرا ابتكارى در تخمين بارامتر در سيستمهاى بيولوزى ارائه

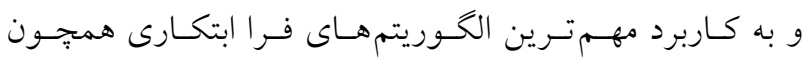

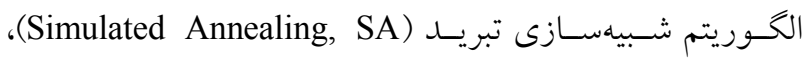


جدول ا. مشخصات ايستخاههاى هيدرومترى مورد مطالعه

\begin{tabular}{|c|c|c|c|c|c|c|}
\hline طول آمار & ارتفاع (متر) & عرض جغرافيايى & طول جغر افيايى & رودخانه & ايستخاه & كد \\
\hline $94-1490$ & rTo & QV-IV-rG & $10-\Delta r-\Delta r$ & تالار & شير كاه & $|4 \circ 0|$ \\
\hline VW-IMG & Y०o & OY-IN-rG & MY-TV-OY & سجادرود & كلو گاه بنديى & $\mid 401 \%$ \\
\hline$V D-I M G V$ & 190 & .1-19-rs & $0 Y-M Y-\Delta r$ & كلارود & ديوا & 14010 \\
\hline$q r-1 r \Delta q$ & 1 & Fr-rtr-rg & $r q-r q-Q r$ & بابلرود & كشتار كاه & $|40| V$ \\
\hline $9 r-|r \wedge|$ & ros & $r r-I r-r q$ & $19-Y Q-Q T$ & بابلك & تمر & $14 \circ \Delta \Delta$ \\
\hline$q r-I r V T$ & Mo & $k r-1 \xi-r g$ & $O r-r V-\Delta r$ & بابلرود & ل بِاشاكلا & $|f \circ V|$ \\
\hline
\end{tabular}

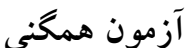

يكى از رايجترين آزمـونهـاى آمـارى بـــاى بررسى وضـعيت

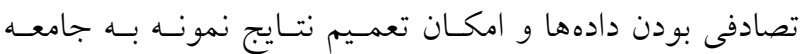
اصلى، آزمون رانتست (Run-Test) اسـت. بـا اسـتفاده از ايسن

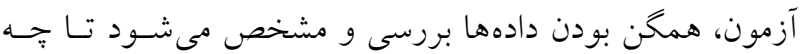
حد دنبالهاى از اعداد بهصورت تصادفى گردآورى شدهاند ( (I).

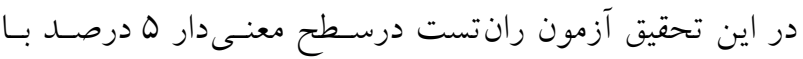

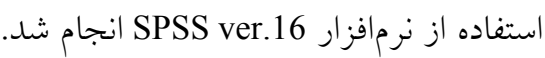

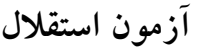
اين آزمون براى بررسى استقلال دادههـاى مشـاهداتى و تـأثير

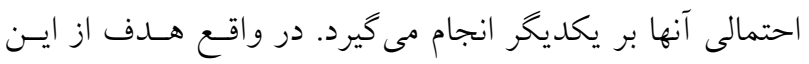

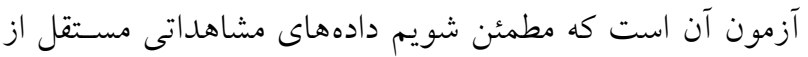

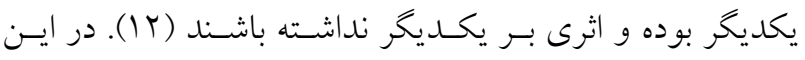

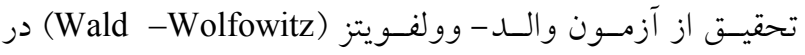
نرمافزار SPSS ver.16 براى بررسى اختلاف معنىدار دو نمونسه مشاهداتى درسطح معنىدار ه درصد استفاده شد.

\section{روش تحقيق}

در اين يُزوهش عملكرد الكوريتم كلونى زنبور عسل در تخمسين روسيق يارامترهاى (موقعيت Location، شكل Shape و مقيـاس Scale) تابع توزيع مناسب، براى تخمين سيلاب منطقـه مـورد مطالعه،، بررسى شده است. در اين راستا توابـع توزيـع احتمـالاتى نظيـر

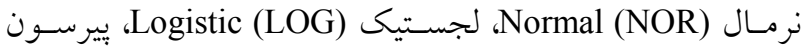

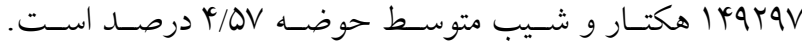

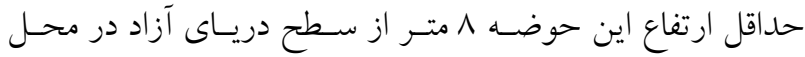
خروجى بابلرود از حوضه (يل محمد حسـن خـان) و بلنــترين نقطه اين حوضه r MVI در جنوب حوضه (جنوب شرق روستاى مهدىخيل) و اقع است. حدود سه درصد از سطح حوضسه عـارى از يوشش كَاهى بوده (ارتفاعـات ضـلع جنـوبى حوضـه) و بقيـهـ سطح حوضه را مرتع، جنگحل و اراضسى زراعسى و بــاغى يوشـانده

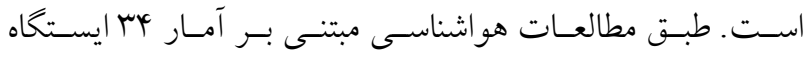

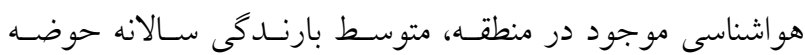

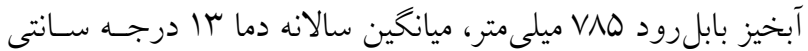

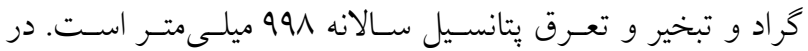
داخل و ييرامون حوضـه با ايستخاه هيـدرومترى شناسـايى و از

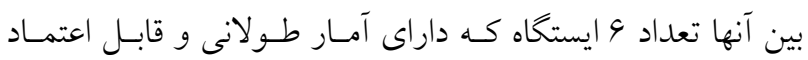

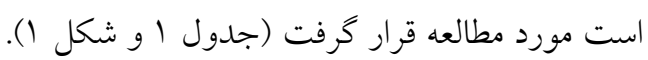

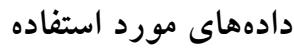
در اين تحقيـق از آمـار و اطلاعـات هواشناسـى و هيــرومترى شركت تحقيقات منابع آب ايران استفاده شده اسـت كـه شـامل آمار دبى حسداكثر جريـان سـاليانه و دبس بيـك، در طـول دوره

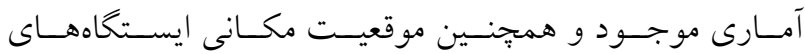
هيدرومترى است. ايستخاههاى هيدرومترى با طول دوره آمـارى ما سـال و بيشـتر اسـتفاده شـــه اسـت (جـــول () و مراحـل آمادهسازى دادهها شامل آزمونهاى همكنى و اسـتقلال دادههـا

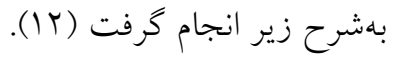




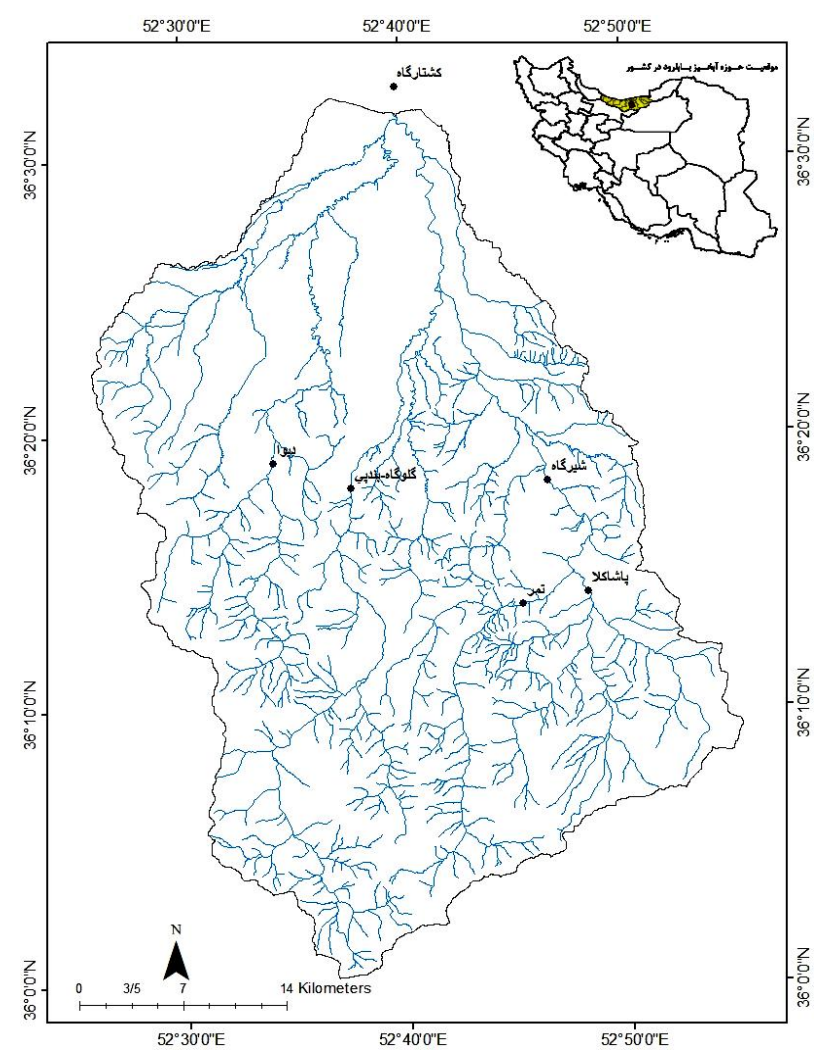

شكل 1. منطقه مورد مطالعه و يراكنش ايستخاههاى هيدرومترى

جدول r. توابع توزيع احتمالاتى مورد مطالعه

\begin{tabular}{|c|c|c|}
\hline Distribution & Probability Distribution Function & Range \\
\hline GEV & $\mathrm{f}_{\mathrm{x}}(\mathrm{x})=\frac{1}{\alpha}\left[1-\beta\left(\frac{\mathrm{x}-\mathrm{u}}{\alpha}\right)\right]^{\left(\frac{1}{\beta}\right)-1} \mathrm{e}\left\{-\left[1-\beta\left(\frac{\mathrm{x}-\mathrm{u}}{\alpha}\right)\right]^{\frac{1}{\beta}}\right\}$ & $-\infty \leqslant x \leqslant u+\alpha / \beta$ \\
\hline GUM & $\mathrm{f}_{\mathrm{x}}(\mathrm{x})=\frac{1}{\alpha}\left(\frac{\mathrm{x}-\gamma}{\alpha} \mathrm{e}^{-\mathrm{e}^{-\frac{\mathrm{x}-\gamma}{\alpha}}}\right)$ & $-\infty<x<\infty$ \\
\hline PE3 & $\mathrm{f}_{\mathrm{x}}(\mathrm{x})=\frac{|\beta|}{\Gamma_{\alpha}}[\beta(\mathrm{x}-\gamma)]^{\alpha-1} \mathrm{e}^{-\beta(\mathrm{x}-\gamma)}$ & $y<x<\infty$ \\
\hline NOR & $f_{x}(x)=\frac{1}{\sqrt{2 \pi \sigma}} e^{-\frac{1}{2}\left(\frac{x-\mu}{\sigma}\right)^{2}}$ & $-\infty<x<\infty$ \\
\hline LOG & $f_{x}(x)=\left(\frac{e^{-\frac{x-\mu}{\sigma}}}{-\frac{x-\mu}{\sigma}}\right)$ & $-\infty<x<\infty$ \\
\hline GAM & $\mathrm{f}_{\mathrm{x}}(\mathrm{x})=\frac{\sigma\left(1+\mathrm{e}^{\sigma}\right)^{2}}{\lambda^{\mathrm{K}} \Gamma(\mathrm{K})} \mathrm{x}^{\mathrm{K}-1} \mathrm{e}^{-\frac{\mathrm{x}}{\lambda}}$ & $0<x<\infty$ \\
\hline
\end{tabular}

جــــول r آورده شـــده اســـت. بـــا اســتفاده از روشههــاى

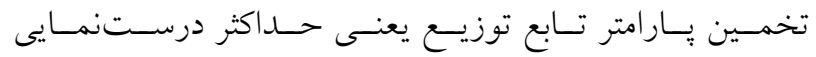
Moments (MOM) Maximum Likelihood (ML)
نوع ץ (Pearson Type 3(PE3)، كمبل (GUMBEL(GUM)، كاما General Extreme Value و مقــادير حـــ Gamma(GAM)

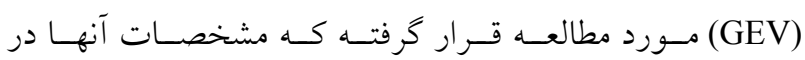




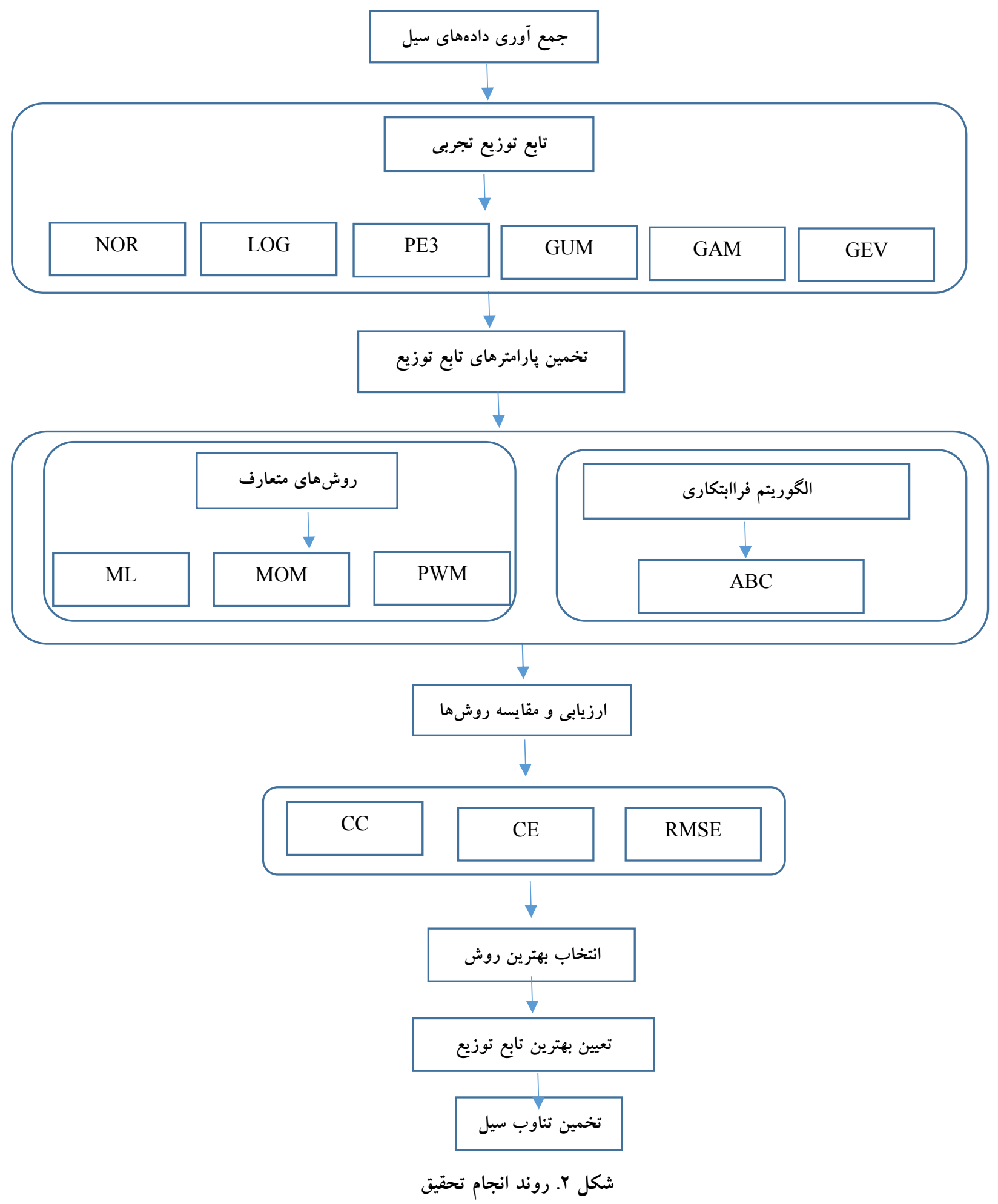

عسل براى تخمين پِارامترهاى توابع توزيع نامبرده استفاده شـــ. و كثـتاور وزنسى احتمـال Probability Weighted Moments

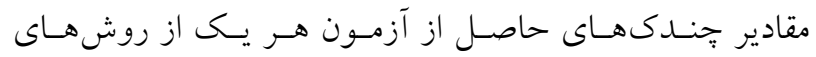

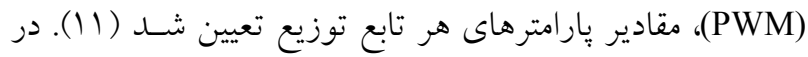

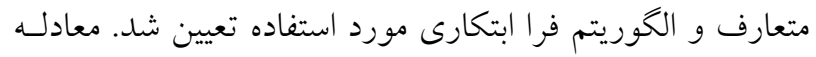
ادامه و مطابق با روند نماى (شـكل r) الخــوريتم كلـونى زنبـور 
ويبـول (Weibull Plotting Position) بـــاى تعيـين دورههــاى زير است:

$$
\mathrm{L}\left(\alpha_{1 .} \alpha_{2 .} \ldots \alpha_{\mathrm{k}}\right)=\prod_{\mathrm{i}=1}^{\mathrm{n}} \mathrm{f}\left(\mathrm{x}_{\mathrm{i}}, \alpha_{1} \cdot \alpha_{2} \ldots \alpha_{\mathrm{k}}\right)
$$

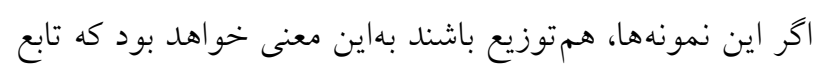

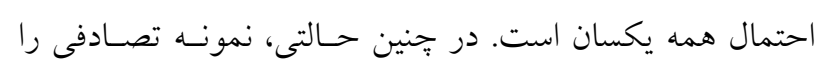
مستقل و همتوزيع مىنامند (ه و 9).

\section{روش گشتاورها}

در روش كشتاورها يُار امترهاى يك تـابع توزيـع احتمـالاتى بـا بسط رابطه بين گشتاورهاى نمونه بـه گشـتاورهاى تـابع توزيـع

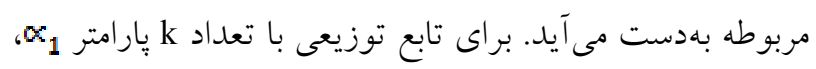

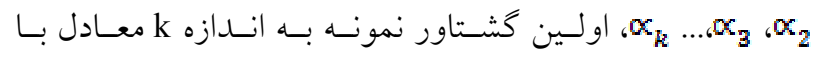
كشتاورهاى جمعيت با يارامترهاى نامعلوم درنظر كرفته مىشود. اين تعداد k معادله بهطور همزمان و براى بارامترهاى ناشـناخته

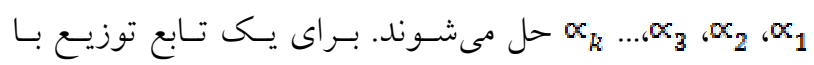
احتمال تجمعى PDF f(x) كشتاور رتبه r عبارتست از (11): $\mu_{\mathrm{r}}^{\prime}=\int_{-\infty}^{+\infty} \mathrm{x}^{\mathrm{r}} \mathrm{f}(\mathrm{x}) \mathrm{dx}$

كشتاورهاى مركزى مربوطه عبارت است از:

$\mu_{r}=\int_{-\infty}^{+\infty}\left(x-\mu_{1}^{\prime}\right)^{r} f(x) d x$

\section{روش كشتاور وزنى احتمال}

كشتاور وزنى احتمال بـراى متغيـر تصـادفى X و و تـابع تجمعى ورى مربوطه بهشكل زير بيان مىشود (1):

$$
\begin{aligned}
M_{\text {p.r.s }}= & E\left\{x^{p}[F(x)]^{\mathrm{r}}[1-F(x)]^{s}\right\}= \\
& \int_{0}^{1} x^{p}[F(x)]^{\mathrm{r}}[1-F(x)]^{\mathrm{s}} d F
\end{aligned}
$$

كه در آن S ، r l اعداد حقيقى هستند. ايسن معادلـه در شـرايط خاصى كه s=0 و p=1 است بهشكل زير خواهد بود: $\beta r=M_{1 . r .0}=E\left\{x[F(x)]^{r}\right\}=\int_{1}^{0} x[F(x)]^{r} d F$.

$$
\mathrm{r}=0.1 .2 . \ldots .
$$

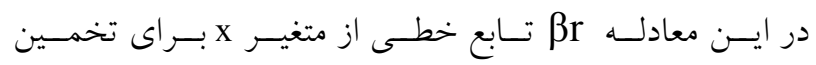
يار امترهاى يك توزيع است

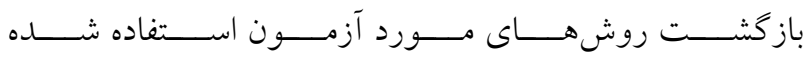

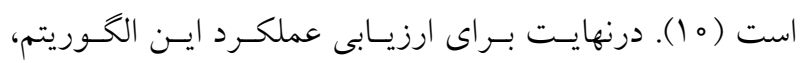

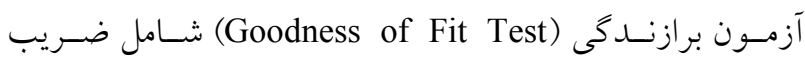
همبسـتخى Correlation Coefficient(CC)، ضـريبتشـخيص Coefficient of Efficiency(CE) خطا Root Mean Square Error (RMSE) در مـورد هريـك از روش هاى فوق انجام و نتايج حاصـل بـا يكـديخر مقايسـه شــ

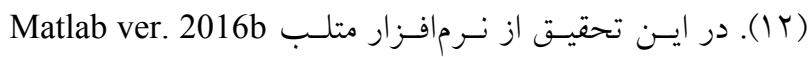
براى توسعه مدل بهينهازى مبتنى بـر الخــوريتم كلـونى زنبـور

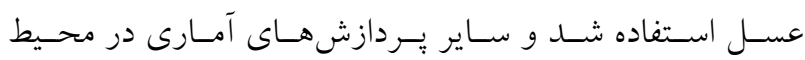
R-Studio

روش هاى تخمين پارامترهاى توزيع احتمالاتى

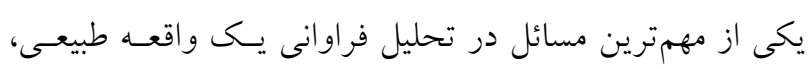

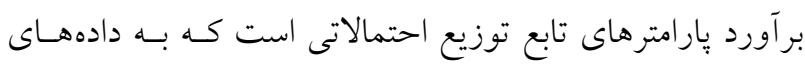

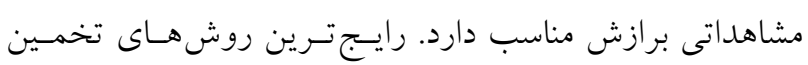
يار امترهاى توابـع توزيـع شـامل روش حهـداكثر درسـتنمـايى، روش گشتاورها، و روش گشتاور وزنى احتمال است (ه و 9).

\section{روش حداكثر درستنمايى}

اصل درستنمايى بيان مى كند (با فرض اينكه مــل مـورد نظـر

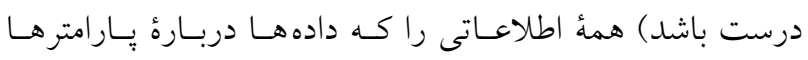
دربرمى گيرند در تابع درستنمايى نهفتـه اسـت. روش حسداكثر تابع درستنمايى بر اين اصل استوار است كه يارامترهاى توزيع

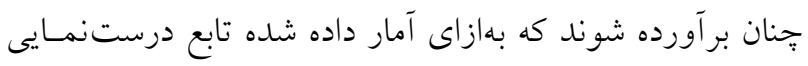

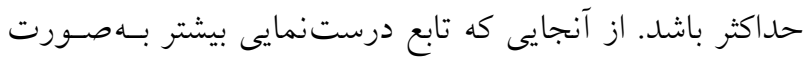

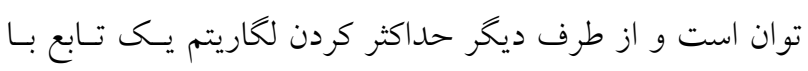
حسداكثر كـردن خــود تـابع هــمارز اسـت لـذا بــراى سـهولت محاسـبات، حـــاكثر درسـتنمـايى روى لخـاريتم تـابع انجـام PDF f(x) مى گيرد. براى يك توزيع مورد نظر با توزيع تجمعى و يار امترهــاى ${ }_{3} \propto_{3}$ 
هـ در صورتى كه بس از تعدادى تلاش يكى منبع غــذايى بهتـر

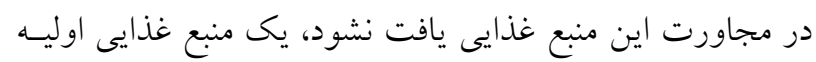

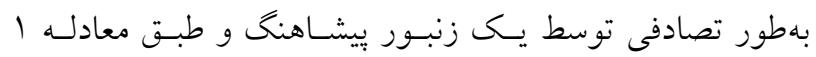
تعيين مى شود. 9. مراحل r تا ه، تا وقتى كه جواب بهينه بهدسـت آيـد، تكـرار مىشود.

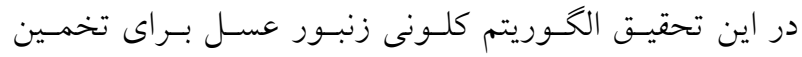
پارامترهاى توابع توزيع استفاده مى شود. براى دستي ديابى به نتايج

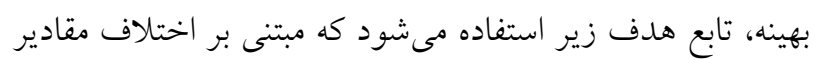
مشاهداتى و تخمينى جريان است (بابع هدو):

$\operatorname{Minimize}\left(O_{b}=\sum_{i=1}^{n}\left(\frac{x_{i}-X_{i}}{x_{i}}\right)^{2}\right)$

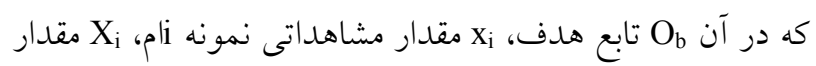

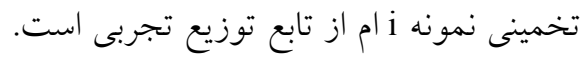

شاخص هاى ارزيابى عملكرد

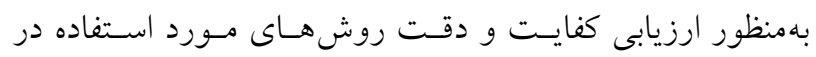

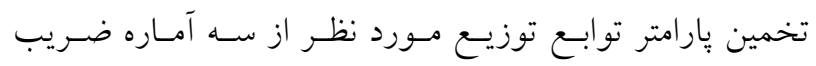

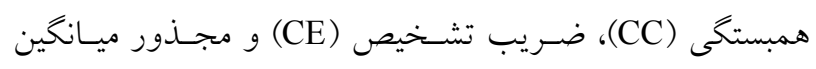

مربعات خطا (RMSE) بهشرح زير استفاده شده است (TQ). $\mathrm{CC}=\frac{\sum_{\mathrm{i}=1}^{\mathrm{n}}\left[\left(\mathrm{x}_{\mathrm{i}}-\overline{\mathrm{x}}\right)\left(\mathrm{X}_{\mathrm{i}}-\overline{\mathrm{X}}\right)\right]}{\left[\sum_{\mathrm{i}=1}^{\mathrm{n}}\left(\mathrm{x}_{\mathrm{i}}-\overline{\mathrm{x}}\right)^{2}\left(\mathrm{X}_{\mathrm{i}}-\overline{\mathrm{X}}\right)^{2}\right]^{0.5}}$

$$
\mathrm{CE}=1-\frac{\sum_{i=1}^{\mathrm{n}}\left(\mathrm{x}_{\mathrm{i}}-\mathrm{X}_{\mathrm{i}}\right)^{2}}{\sum_{i=1}^{\mathrm{n}}\left(\mathrm{x}_{\mathrm{i}}-\overline{\mathrm{X}}\right)^{2}},-\infty \leq \mathrm{CE} \leq 1
$$

$\operatorname{RMSE}=\left[\frac{1}{\mathrm{n}} \sum_{\mathrm{i}=1}^{n}\left(\mathrm{x}_{\mathrm{i}}-\mathrm{X}_{\mathrm{i}}\right)^{2}\right]^{0.5}, 0 \leq \mathrm{RMSE} \leq \infty$

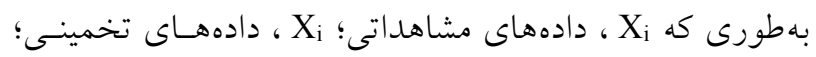

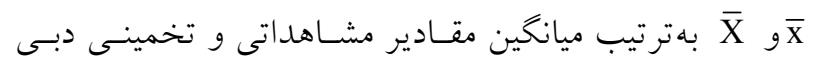

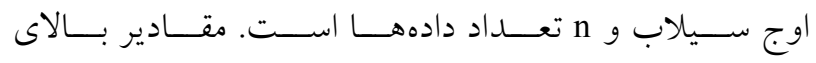
ضريب همبستخى و ضريب تشخيص و مقادير بـايين مجـذور ميانكين مربعات خطا عملكرد مناسب روش مورد نظر است.
Artificial Bee Colony (ABC) الخوريتم كلونى زنبور عسل

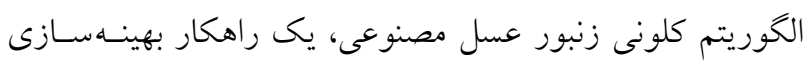

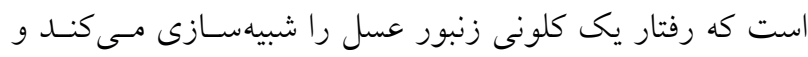

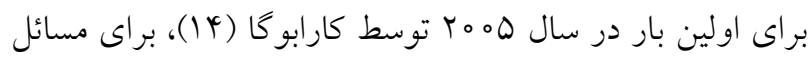
بهينهسازى ارائه شد. در اين الكوريتم، يكى منبع غذايى بهلعنـوان هدفى در فضاى جستجو تعريف مىشـود (يـى راهكـار بـراى

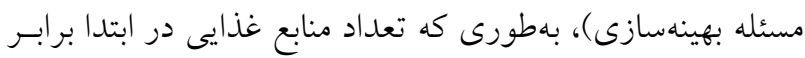

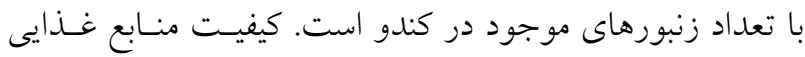
توسط مقدار تابع هدف در آن موقعيت (ميزان برازندكى) تعيسين مىشود.

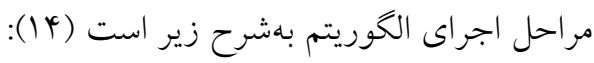

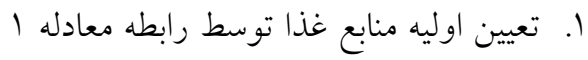
$\mathrm{x}_{\mathrm{ij}}=\mathrm{x}_{\mathrm{j}}^{\min }+\operatorname{rand}(0.1)\left(\mathrm{x}_{\mathrm{j}}^{\max }-\mathrm{x}_{\mathrm{j}}^{\min }\right)$

بهورى كه SN تعداد منابع غــاء

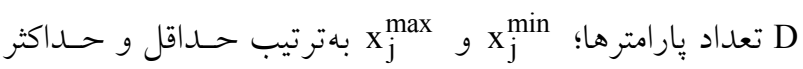

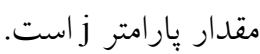
ז. حركت زنبورهاى كاركر بهسمت منابع غـذا و تعيسين منـابع غذايى مجاور طبق معادله r:

$$
\mathrm{V}_{\mathrm{ij}}=\mathrm{x}_{\mathrm{ij}}+\phi_{\mathrm{ij}}\left(\mathrm{x}_{\mathrm{ij}}-\mathrm{x}_{\mathrm{kj}}\right)
$$

در اين معادله j و k بـهترتيـب بارامترهـاى منتخـب تصـادفى و همسايخان تصادفى، و

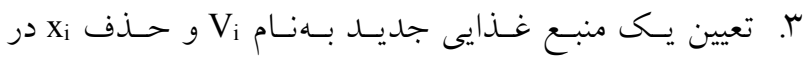

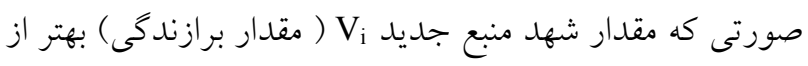
منبع قبل Xi مباشد. Y

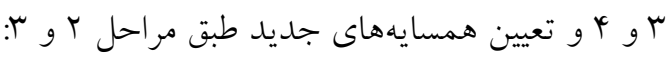

$$
\begin{gathered}
\mathrm{p}_{\mathrm{i}}=\frac{\text { fitness }_{\mathrm{i}}}{\sum_{\mathrm{j}=1}^{\mathrm{SN}} \text { fitness }_{\mathrm{i}}} \\
\text { fitness }_{\mathrm{i}}= \begin{cases}\frac{1}{1+\text { fit }_{\mathrm{i}}} . & \text { fit } \geq 0 \\
1+\text { abs }_{\left(\text {fit }_{\mathrm{i}}\right) .} & \text { fit }_{\mathrm{i}}<0\end{cases}
\end{gathered}
$$

بهورى كه fiti ، هزينه (مقدار تابع هدف) براى منبع غـذا ل مقدار شهد (برازش) منبع غذا Xitness 
مقياس) توابع توزيـع مختلـف در ايستخاهــاى مطالعـاتى بـا

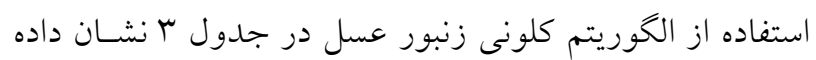

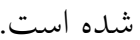

\section{نتايج آزمون برازندگى}

بهمنظور بررسى عملكرد الكوريتم كلونى زنبور عسل در تخمين

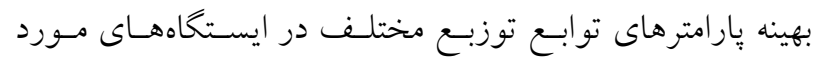

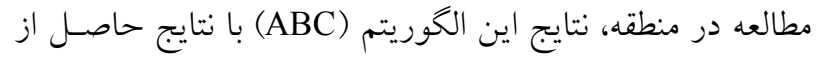

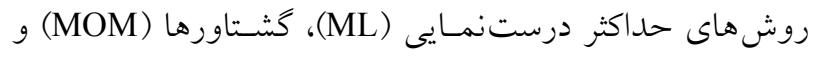

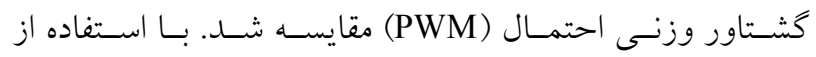
معادلات || تا با مقادير آمارههـاى ضـريب همبستستى (CC)،

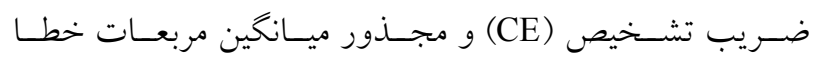

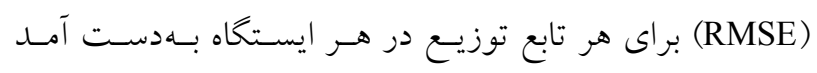

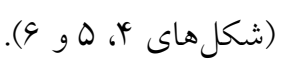

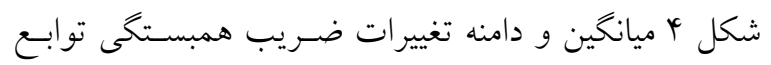

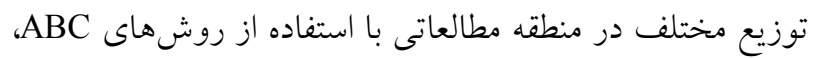

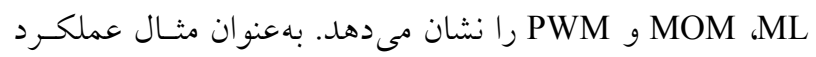

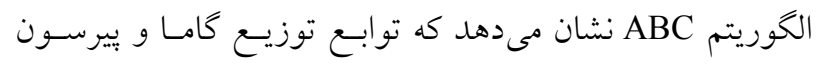

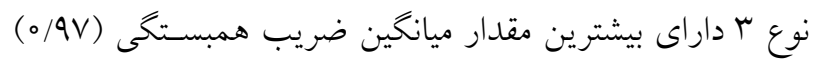

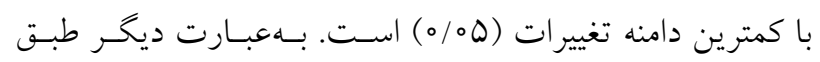

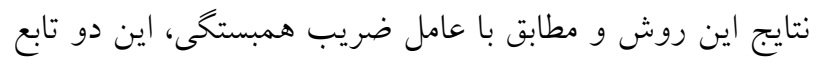

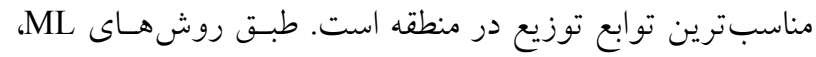

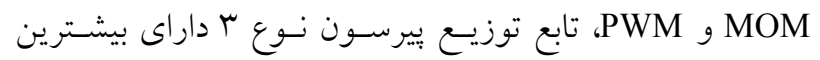

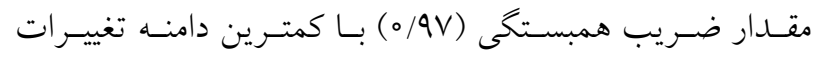
(\% (\% در منطقه است. مقايسه عملكرد جهار روش فوق نشان مى دهد كه تابع توزيـع بيرسـون نـوع ب داراى بيشـترين مقـدار

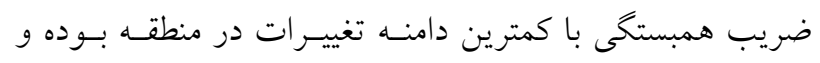

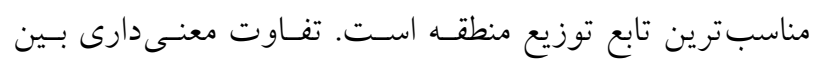
جهار روش فوق از لحاظ آماره ضريب همبستخى وجود ندارد.

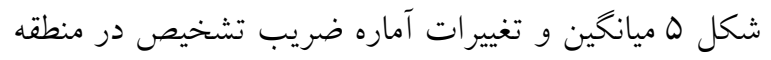

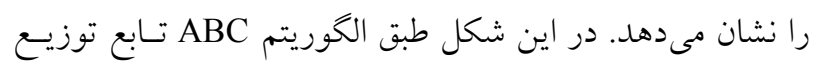

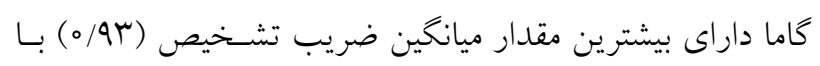

\section{نتايج و بحث}

در اين تحقيق نخست دادههاى دبى حداكثر سالانه ايستخاههـاى

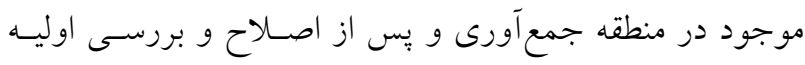
صحت و درستى دادهها مورد استفاده قرار كرفت. بـا استفاده از

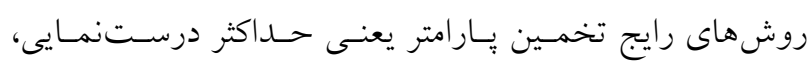

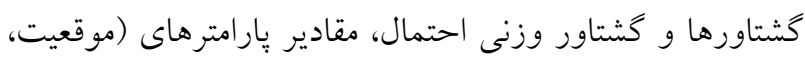

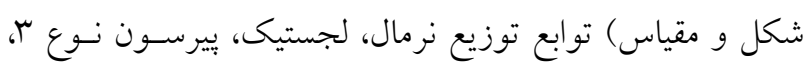
كمبل، كاما و مقادير حد در ايستخاههاى مـورد مطالعسه تخمسين

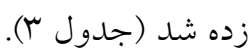

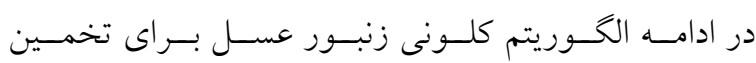
يارامترهاى توابع توزيع در ايستخاههاى مطالعاتى به كـار كرفتسه

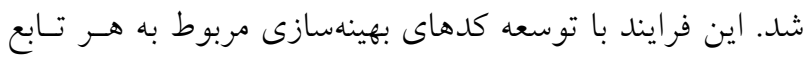

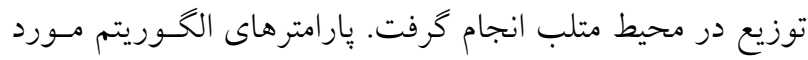

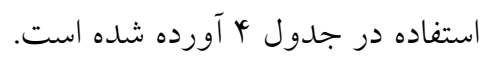

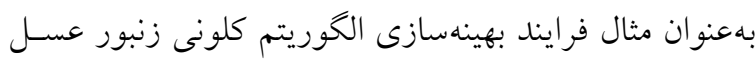

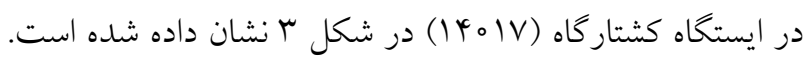
همانطسور كـه در ايسن شـكل ديسـده مسى شـود مقــدار خطـا در

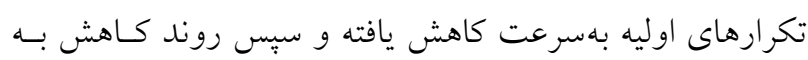

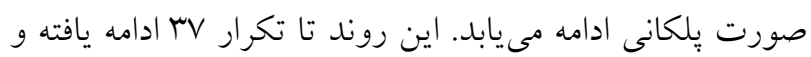
سبس خطا به مقدار ثابت مىرسد. بهعبارت ديخر تعـداد تكـرار

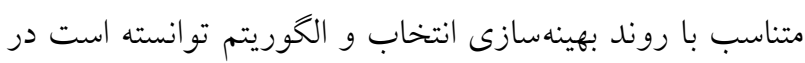
بازه تعداد تعريف شده تكرار به جواب قطعى برسد.

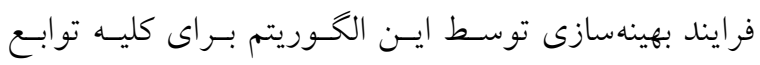

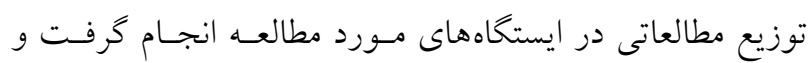

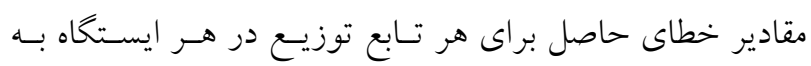

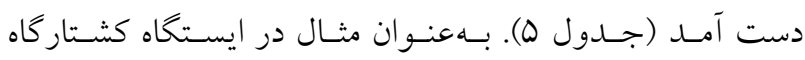
(I I \& IV) كمترين مقدار خطاى مدل را نشان مىدهند.

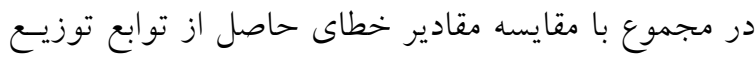

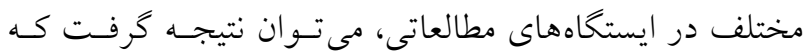

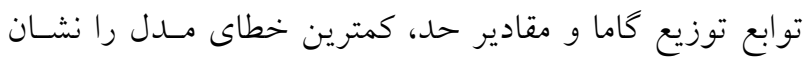

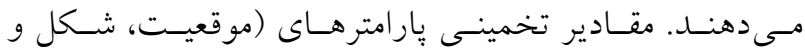




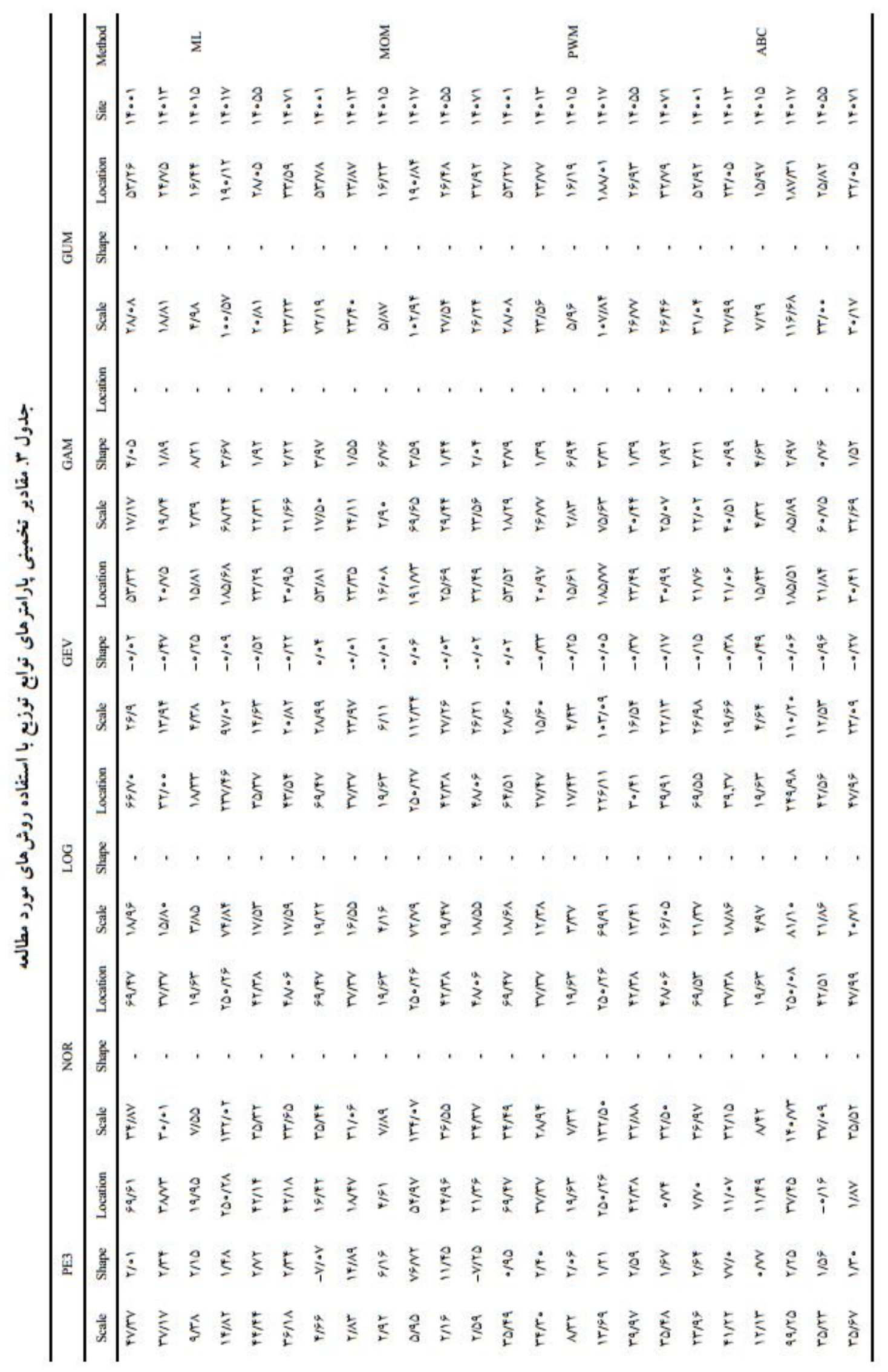


جدول † ا مقادير تعريف شده بارامترهاى الكوريتم كلونى زنبور عسل

\begin{tabular}{ccc}
\hline Acceleration Coefficient Upper Bound & مقصيف \\
\hline 10 & Abandonment Limit Parameter & $\mathrm{a}$ \\
\hline 10 & Colony Size & $\mathrm{L}$ \\
100 & Maximum Number of Iteration & $\mathrm{n}$ \\
10 & Number of Onlooker Bees & $\mathrm{m}$ \\
\hline
\end{tabular}

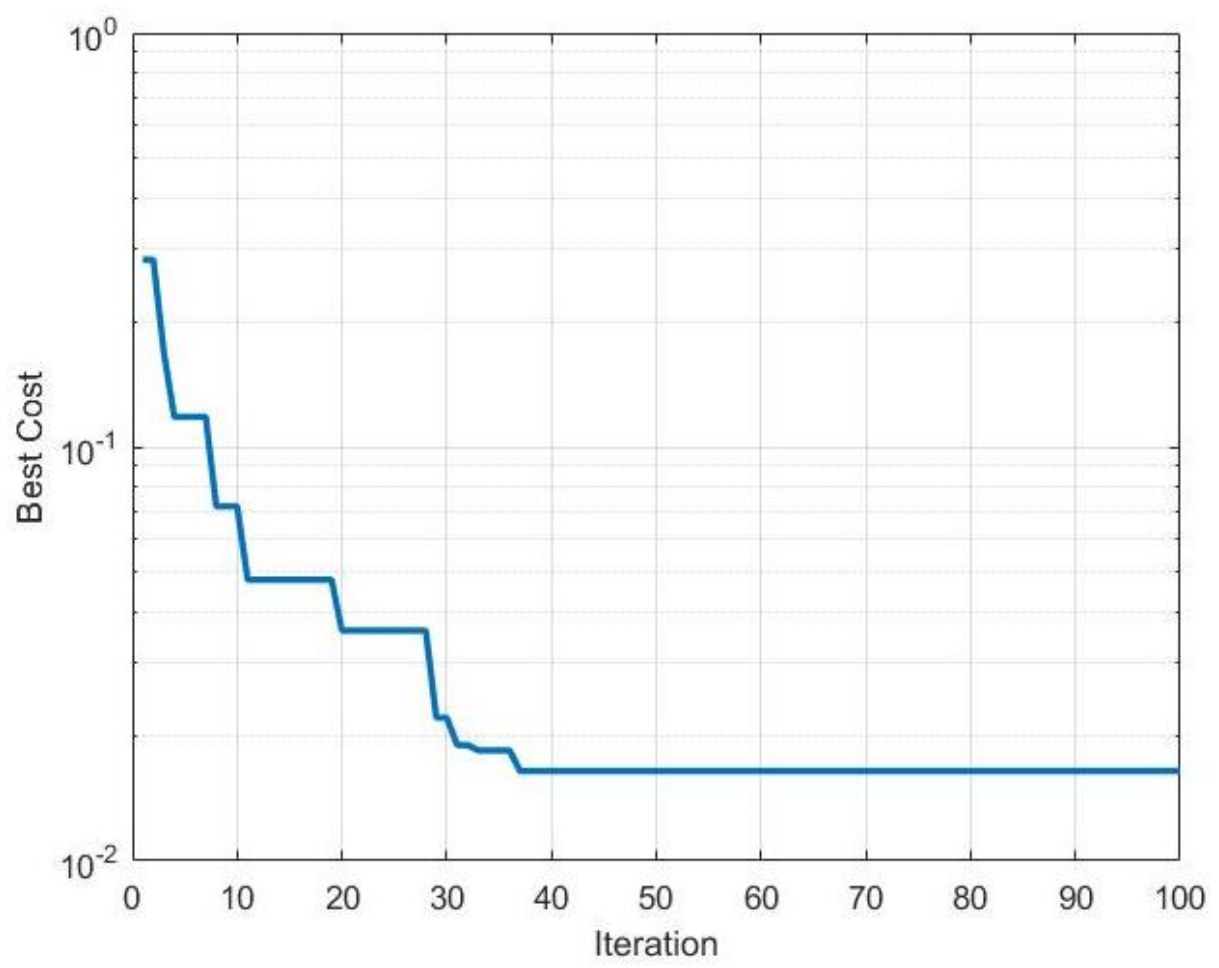

شكل r. تغييرات خطاى الكوريتم كلونى زنبور عسل در تخمين بهينه هارامترهاى تابع توزيع كاما در ايستخاه كشتاركاه

جدول ه. مقادير خطاى الكوريتم ACO در تخمين بارامترهاى توابع توزيع در ايستخاههاى مطالعاتى

\begin{tabular}{|c|c|c|c|c|c|c|}
\hline PE3 & NOR & LOG & GEV & GAM & GUM & ايستگاه \\
\hline ס ., & $\cdot, \cdot \wedge$. & $\cdot, \Delta r$ & , , TV & צr., & , , r & 14001 \\
\hline זه., &., 19. & ., &., $.4 \lambda$ &., $.4 \lambda$ & $\cdot, 1$ & $1401 \pi$ \\
\hline., .94 & 多 & ., 11. & .,. . & 111, & $\cdot, 1 \cdot v$ & 14010 \\
\hline., .19 &., .99 &., $.9 \mathrm{~V}$ &., .19 &., .19 &., .11 & $\left|f_{0}\right| V$ \\
\hline., 11. & 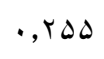 & $\cdot, r \Delta l$ & rו.,. & $\cdot, \cdot V Y$ &., 10 . & $14 \circ \Delta \Delta$ \\
\hline .,. & Vri, & ג'ו, & ., ro & נr.,. &.,$\Delta t$ & $|r \circ v|$ \\
\hline
\end{tabular}


$\mathrm{ABC} C \mathrm{C}$

$\square$ GUM $\square$ GAM $\square$ GEV $\square$ LOG $\square$ NOR $\square$ PE3

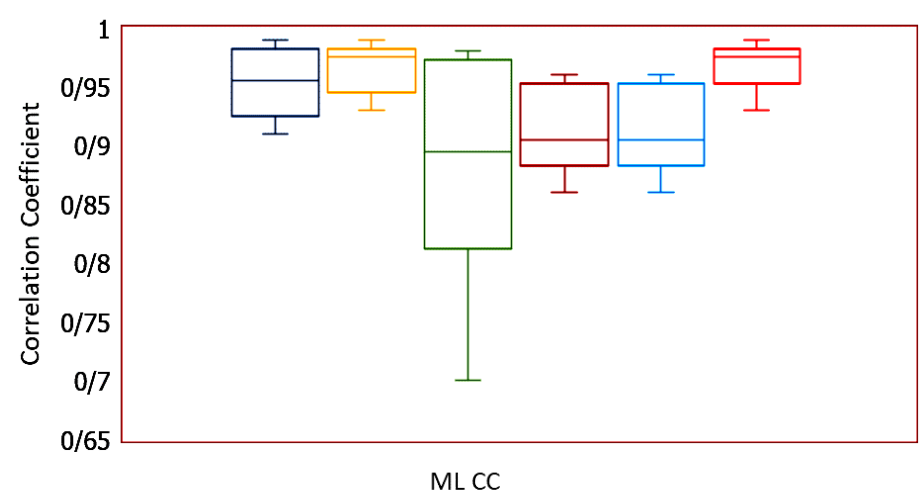

$\square$ GUM $\square$ GAM $\square$ GEV $\square$ LOG $\square$ NOR $\square$ PE3

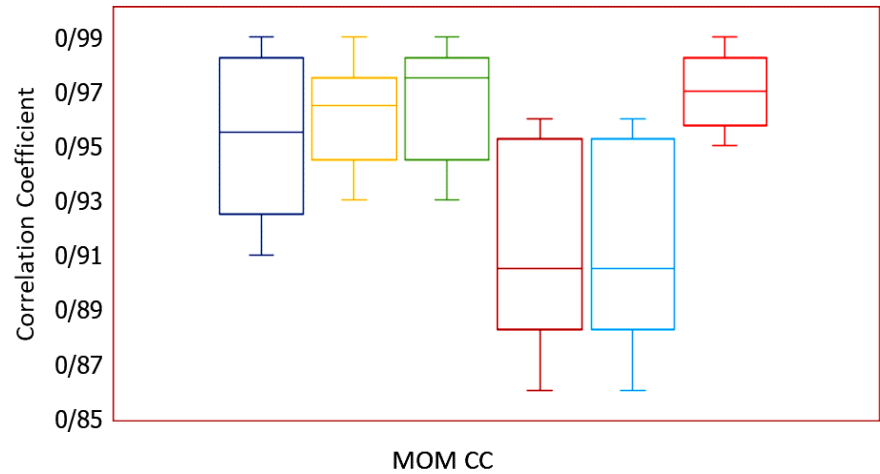

$\square$ GUM $\square$ GAM $\square$ GEV $\square$ LOG $\square$ NOR $\square$ PE3

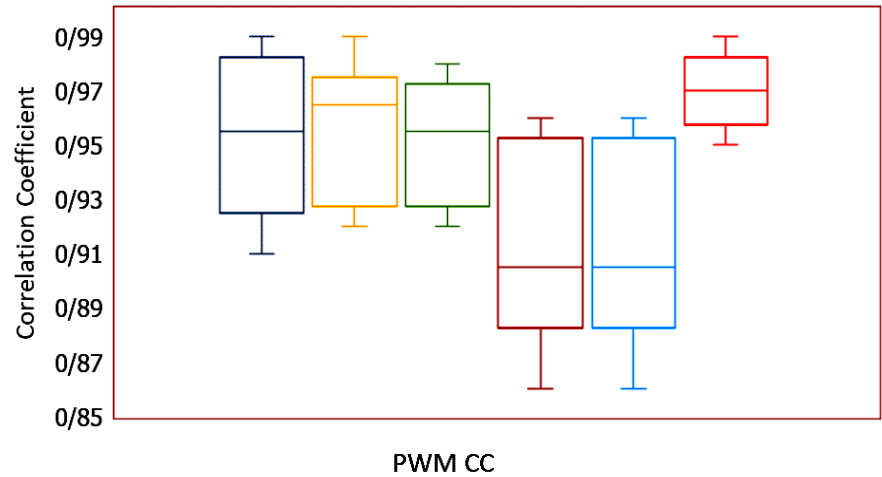

$\square$ GUM $\square$ GAM $\square$ GEV $\square$ LOG $\square$ NOR $\square$ PE3

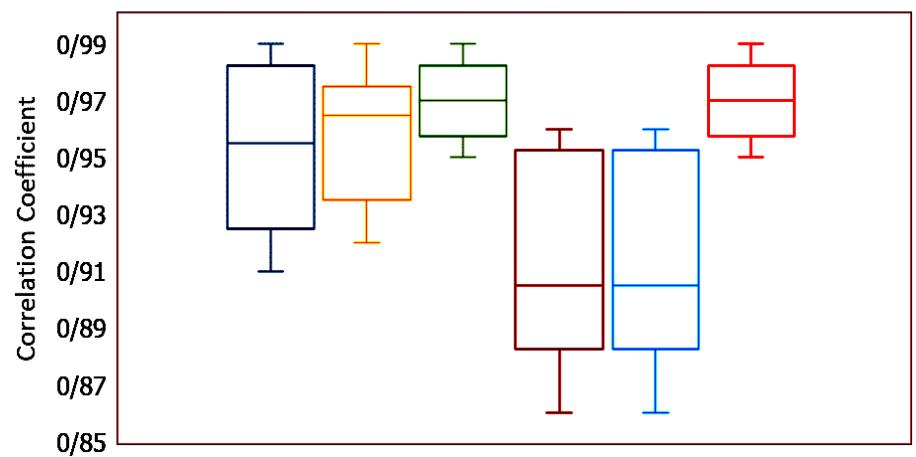

شكل †ا. مقايسه تغييرات ضريب همبستخى روشهاى مورد مطالعه در تخمين پِارامترهاى توابع توزيع 
ABC CE

$\square$ GUM $\square$ GAM $\square$ GEV $\square$ LOG $\square$ NOR $\square$ PE3

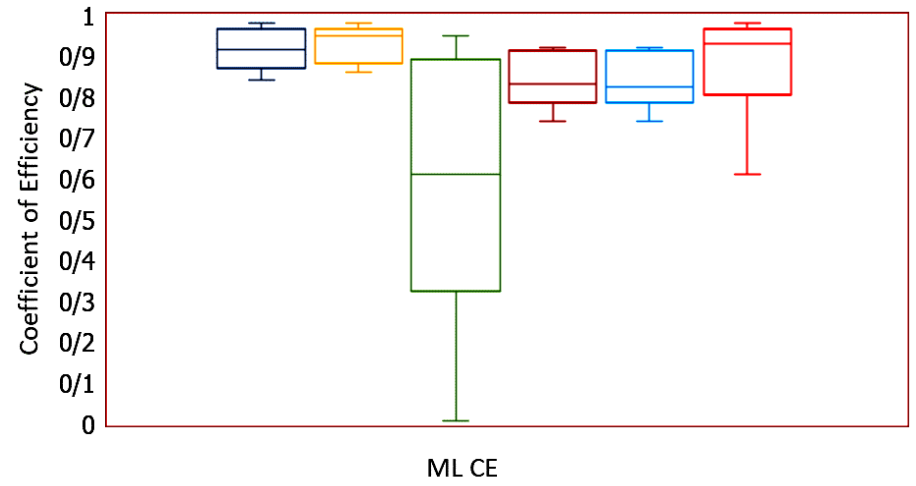

$\square$ GUM $\square$ GAM $\square$ GEV $\square$ LOG $\square$ NOR $\square$ PE3

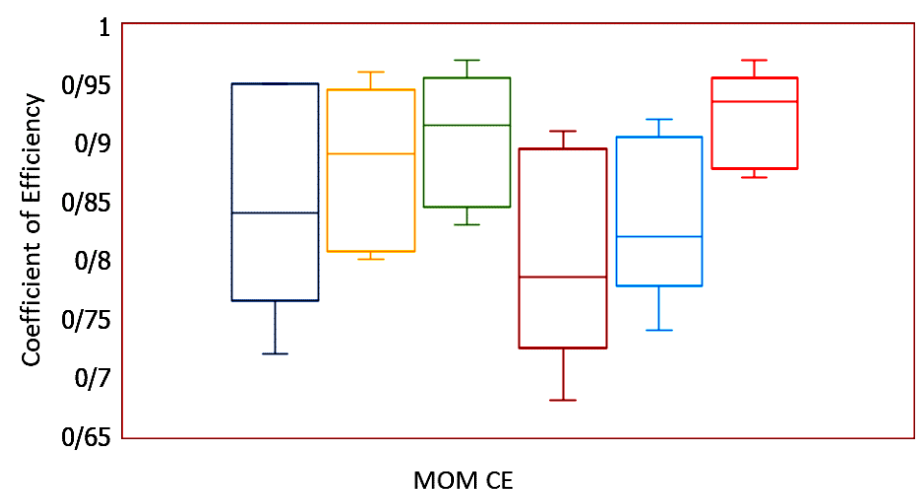

$\square$ GUM $\square$ GAM $\square$ GEV $\square$ LOG $\square$ NOR $\square$ PE3

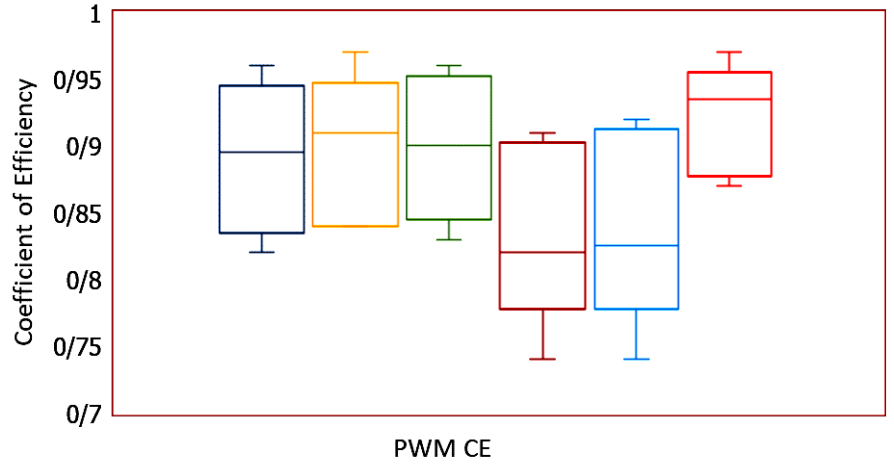

$\square$ GUM $\square$ GAM $\square$ GEV $\square$ LOG $\square$ NOR $\square$ PE3

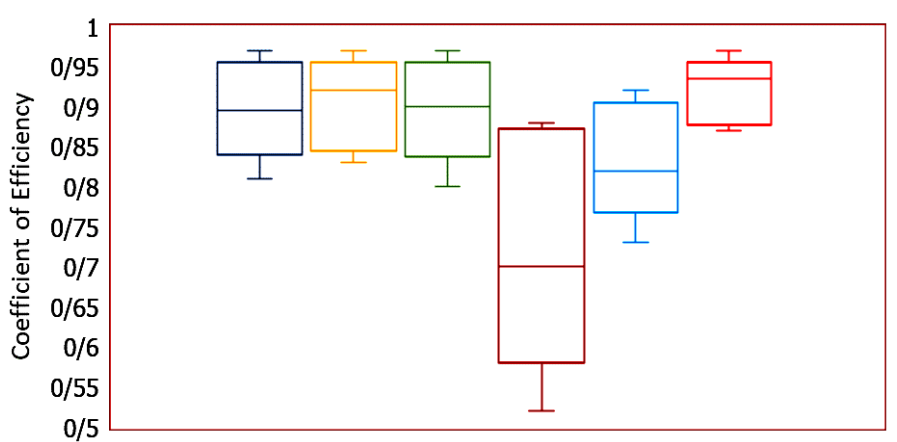

شكل ه. مقايسه تغييرات ضريب تشخيص روشهاى مورد مطالعه در تخمين بارامترهاى توابع توزيع 
مورد مطالعه توزيع كاما اسـت. نتـايج ايسن جـــول و نمودارهـا نشان مىدهد كه اين تابع توزيع كمترين خطاى تخمسين يـارامتر

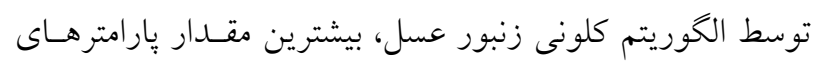

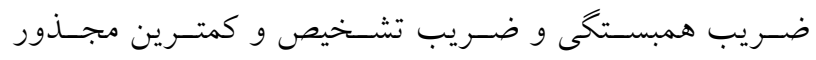

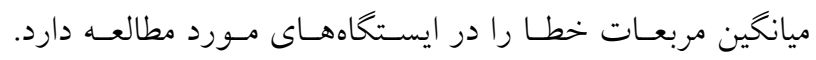

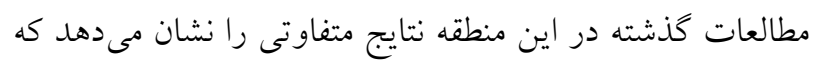
مى تواند بهعلت روش تخمسين پـارامتر و هميجنسين طـول دوره

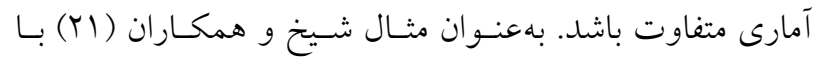

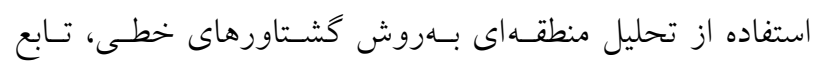

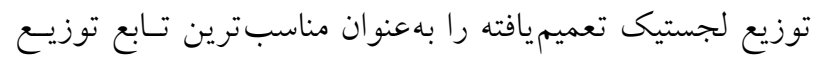

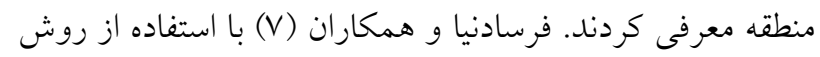

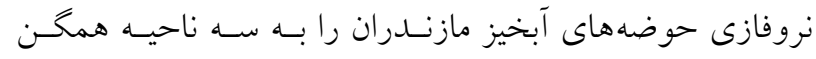

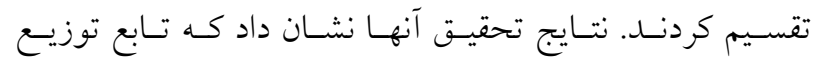

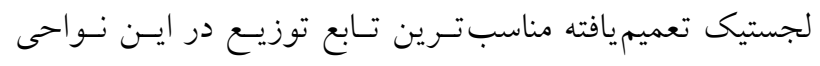

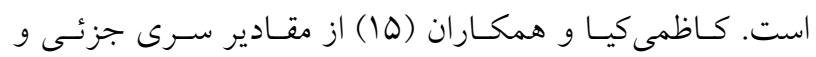

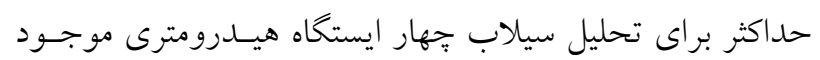

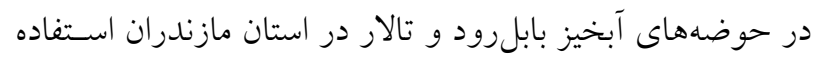

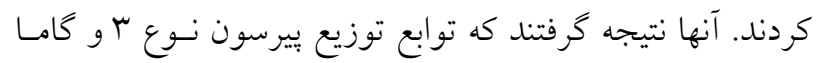
مناسبترين توابع توزيع بهترتيب در ايستخاههاى شير كاه-ت تسالار

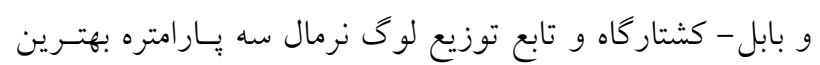
تابع توزيع در ايستكاههاى كياكلا و قرآنتالار است.

تخمين تناوب سيل در منطقه

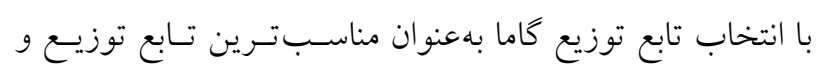

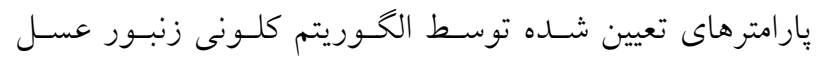

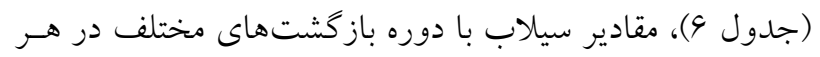

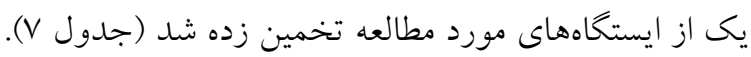

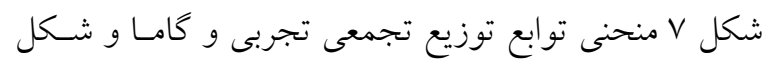

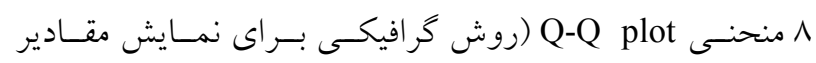

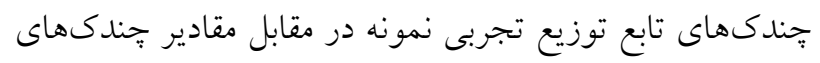

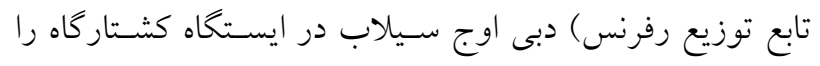

كمترين دامنه تغييرات (0/0/0) است درحالى كـه طبـق عملكـرد ساير روشها، تابع توزيع ييرسون نوع ب داراى بيشـترين مقـدار

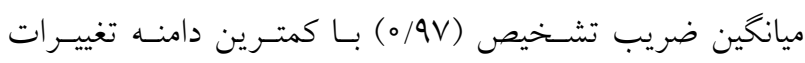

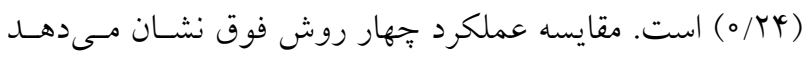

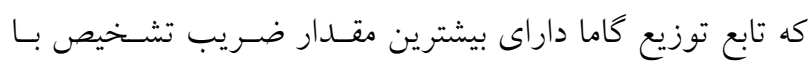

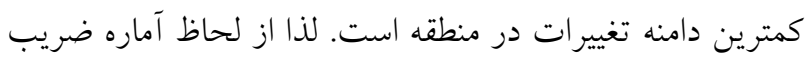

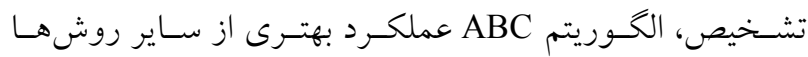
داشته و تابع توزيع كاما بهترين تابع توزيع در منطقه است.

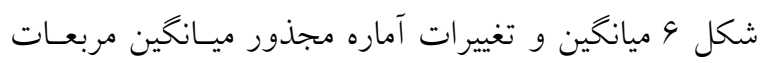
خطا در منطقه را نشان مىدهـــ. در ايسن شـكل طبـق الخـوريتم

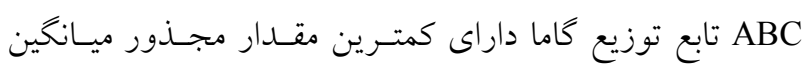

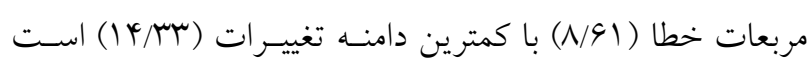
درحاليكه طبق روشهاى ML و MOM و PWM كمترين مقـدار

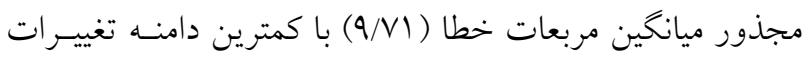

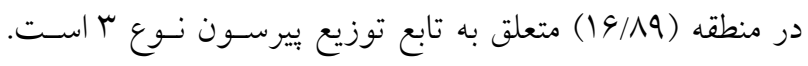

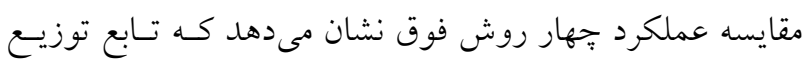

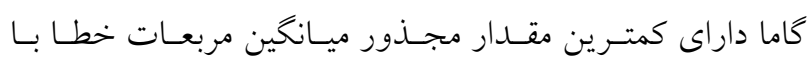

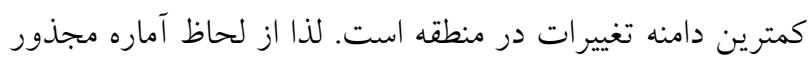

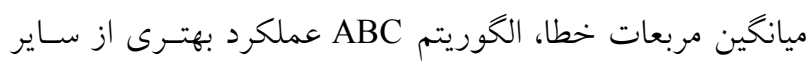

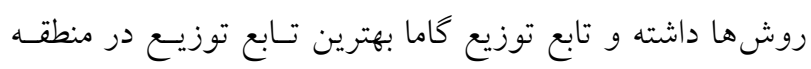
درنهايـت بـا جمـعبنــى نتـايج حاصـل از هـر سـهـ آمـاره

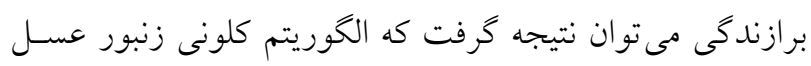

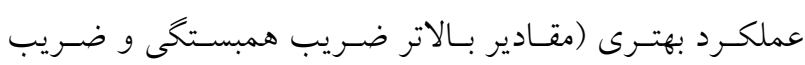

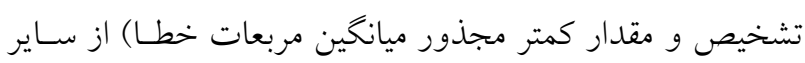

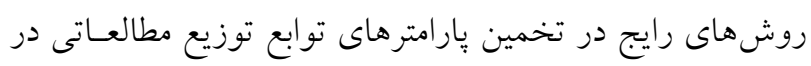

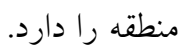
انتخاب تابع توزيع مناسب در منطقه

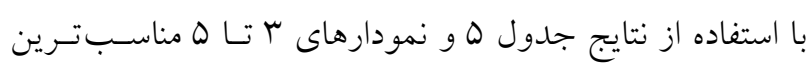

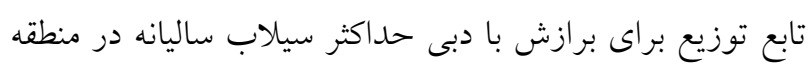


ABC RMSE

$\square$ GUM $\square$ GAM $\square$ GEV $\square$ LOG $\square$ NOR $\square$ PE3

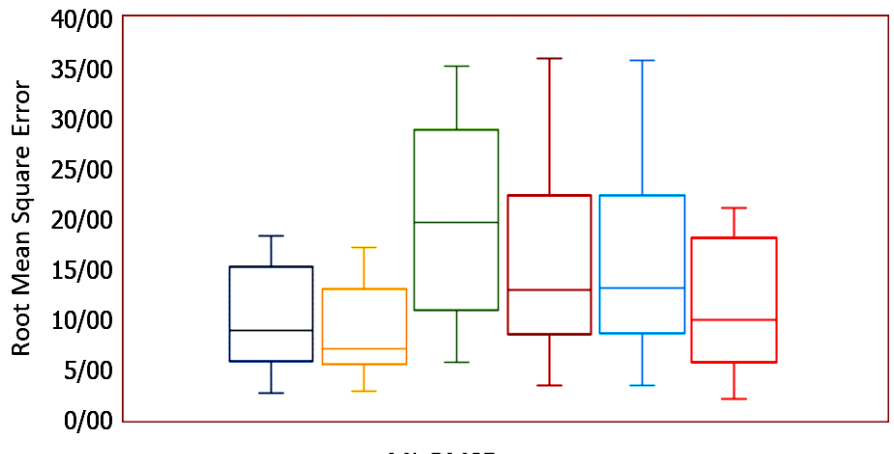

ML RMSE

$\square$ GUM $\square$ GAM $\square$ GEV $\square$ LOG $\square$ NOR $\square$ PE3

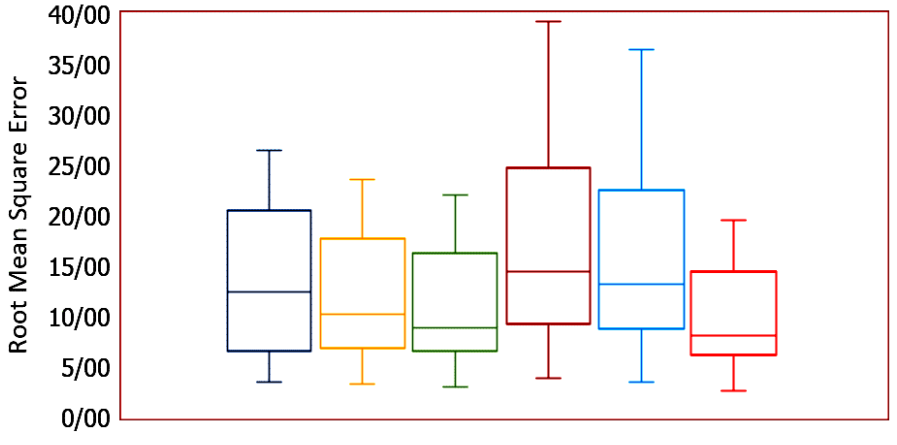

MOM RMSE

$\square$ GUM $\square$ GAM $\square$ GEV $\square$ LOG $\square$ NOR $\square$ PE3

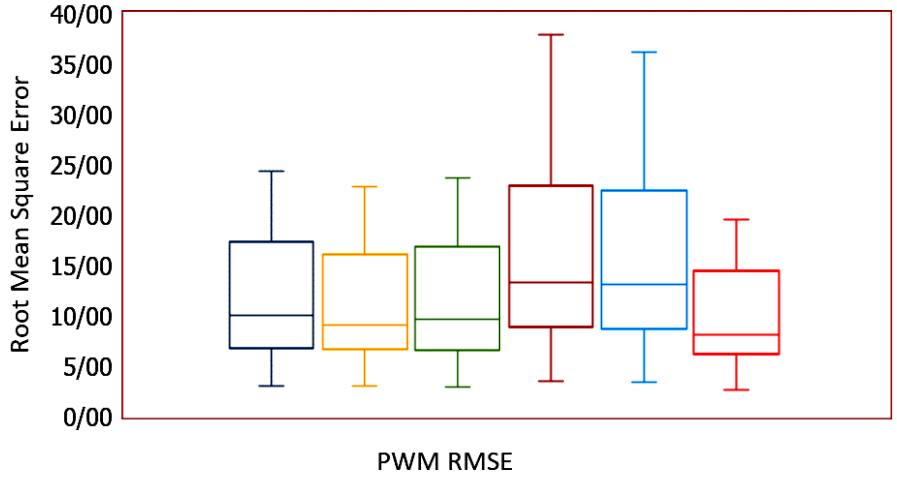

$\square$ GUM $\square$ GAM $\square$ GEV $\square$ LOG $\square$ NOR $\square$ PE3

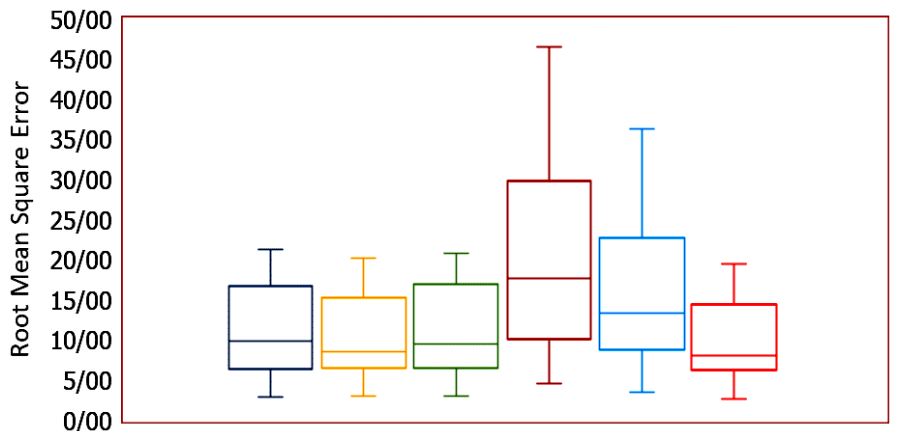

شكل 9. مقايسه تغييرات مجذور ميانگين مربعات خطاى روشهاى مورد مطالعه در تخمين يار امترهاى توابع توزيع 
جدول 9. مقادير بارامترهاى تخمينى تابع توزيع گاما توسط الخوريتم كلونى زنبور عسل در ايستخاههاى مطالعاتى

\begin{tabular}{|c|c|c|}
\hline Scale & Shape & ايستخاه \\
\hline TY/OT & $r / r \circ q$ & $|400|$ \\
\hline$Y \circ / D 1$ &.$/ 99$ & $|k \cdot| r$ \\
\hline T/MT & $r / 9 \mu$ & 14010 \\
\hline$\wedge \Delta / \wedge q$ & $r / 990$ & $|40| V$ \\
\hline$G \circ / N D$ & $\circ / V G$ & $14 \circ \Delta \Delta$ \\
\hline$r Y / 9 q$ & $1 / D T$ & $|f \circ V|$ \\
\hline
\end{tabular}

\begin{tabular}{|c|c|c|c|c|c|c|}
\hline 100 & $\omega_{0}$ & ro & 10 & $\Delta$ & $r$ & ايستخاه/سال \\
\hline $4 \pi / 4 \lambda$ & $r V / T T^{4}$ & $T V / T$ & $r 0 / 41$ & $|\varphi / 4|$ & $11 / \pi r$ & $|400|$ \\
\hline$T V / 9 Q$ & N/A ${ }^{*}$ & $4 / 10$ & $r$ & oNA & $0 \mu \wedge$ & $1401 \%$ \\
\hline $\mid N / \Delta \Lambda$ & $1 Y / \circ V$ & $9 / \pi 9$ & V/DT & $\Delta / V Q$ & $Y / V V$ & 14010 \\
\hline TYG/GN & $1 K Q / 94$ & AT/AT & $9 N / V_{0}$ & $F V / Q \circ$ & re/4T & $1401 V$ \\
\hline$T N / \circ D$ & $9 / 90$ & $r / 9 \Lambda$ & $1 / 09$ & $\circ M$ & $0 / 14$ & $14 \circ \Delta 0$ \\
\hline$r q / \pi q$ & $19 / \mathrm{AV}$ & $9 / 19$ & $0 / 91$ & $r / N V$ & $1 / 91$ & $|4 \circ V|$ \\
\hline
\end{tabular}

Empirical CDF for $\mathbf{x}$ (solid line) with Fitted Gamma CDF (dashed line)

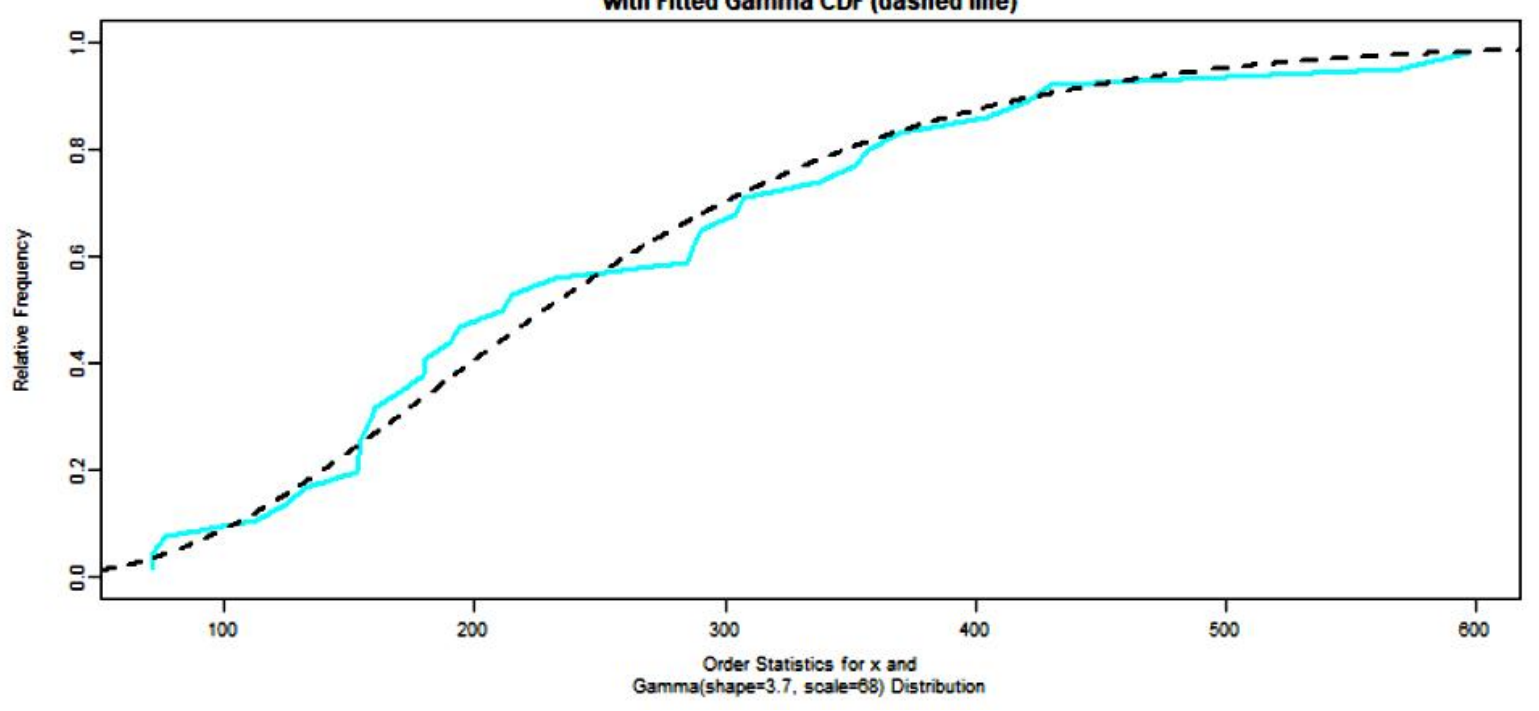

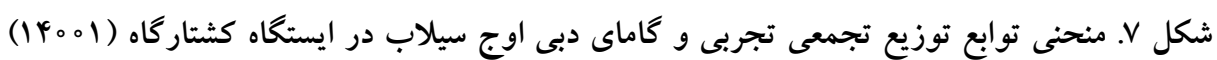


Q-Q Plot for $\mathbf{x}$ Fitted to

Gamma Distribution, with 0-1 Line

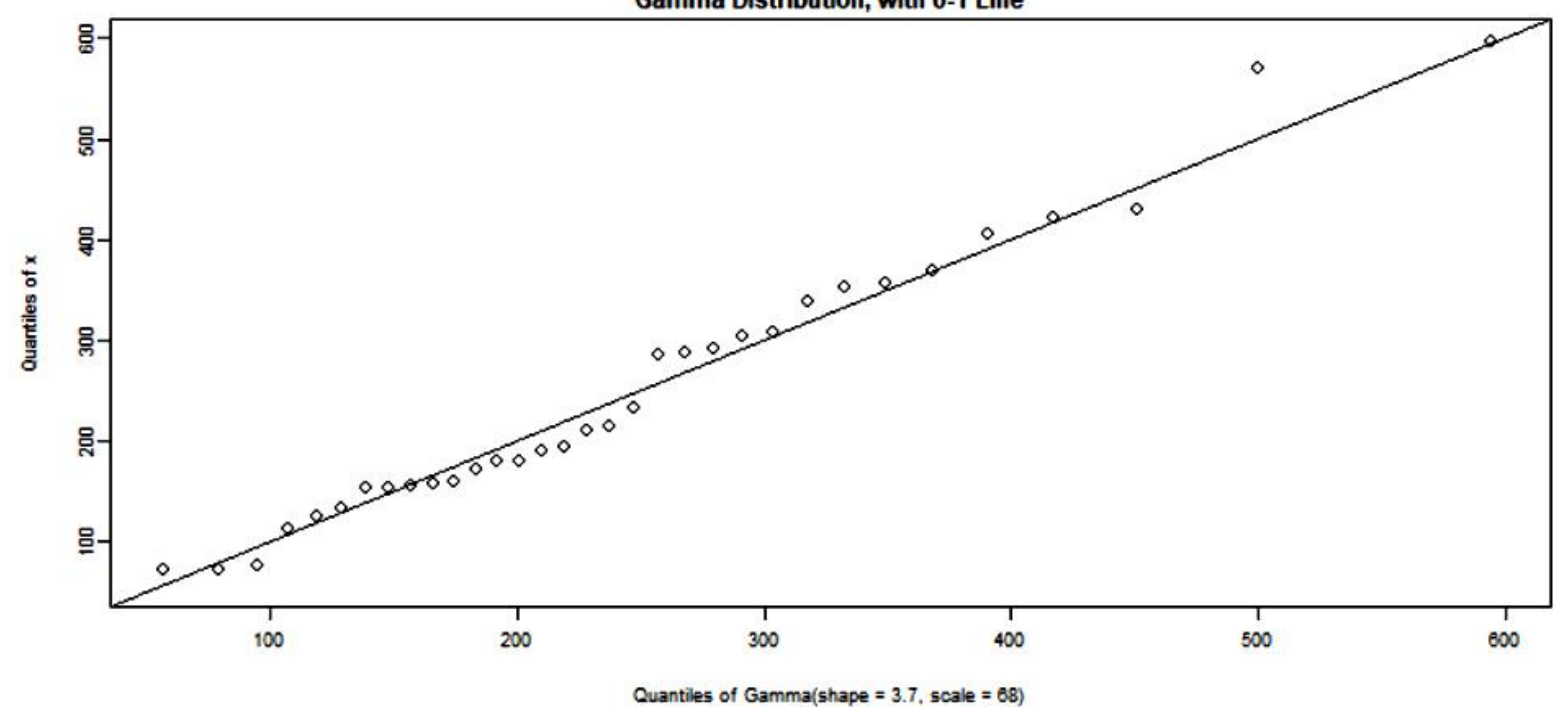

شكل ^ـ منحنى Q-Q plot دبى اوج سيلاب در ايستخاه كشتار كاه ( (F.01)

الخوريتم كلونى زنبور عسل در قيـاس بـا روشهـاى متعـارف تخمين پارامتر نشان داده شد. بهترين عملكرد اين الكوريتم در تخمين يارامتر مربوط به توابع توزيع گاما و مقادير حسـ بـوده

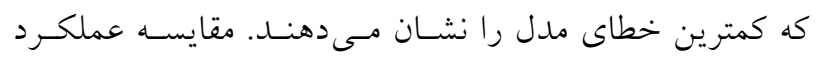
روش هاى MOM و ML ABC و PWM در برآورد سـه آمـاره برازندكى نشان مى دهد كه تابع توزيـع بيرسـون نـوع ب داراى

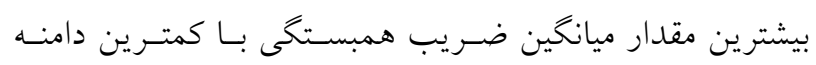

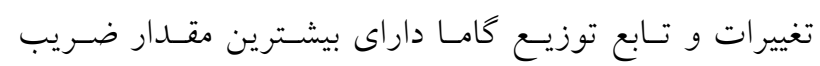
تشخيص با كمترين دامنه تغييرات و همجيخنين كمتـرين مقـدار مجذور ميانخين مربعات خطا با كمترين دامنه تغييـرات اسـت. مناسبترين تابع توزيع براى برازش با دبسى حسداكثر سـيلاب

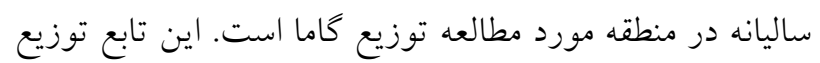
كمترين خطاى تخمين يارامتر توسط الخـوريتم كلـونى زنبـور

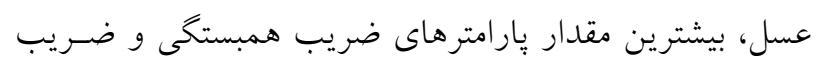
تشخيص و كمترين مقدار مجذور ميانخين مربعات خطـا را در ايستخاههاى مورد مطالعه دارد. درنهايت با جمـع بنـدى نتـايج بهدست آمده مى توان نتيجه كرفت كه الكوريتم كلـونى زنبـور عسـل عملكــرد بهتـرى (مقـادير بـالاتر ضـريب همبسـتخى و ضريب تشخيص و مقدار كمتر مجذور ميانخين مربعات خطـا)
نشان مىدهد. طبق تعريـف، در نمـودار Q-Q plot، هــر جقعـدر

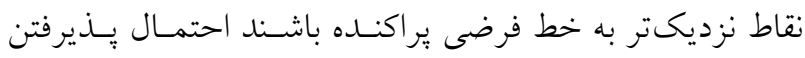
فرض صفر بيشتر است. بهعبارت ديخر دادههاى مورد مطالعه از تابع توزيع مورد نظر بيروى مى كند.

\section{نتيجه كيرى}

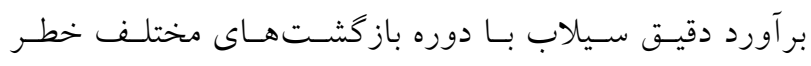
شكست سازههاى كنترل جريان (بهواسطه برآورد كم جريـان) و هزينههاى ساخت آن را (بهواسـطه بـر آورد بيشـينه جريـان) كاهش مى دهد. بهو اسـطه طـول آمـارى كوتـاهمــات سـيلاب مشاهداتى و مكانيسم غيرخطى آن، تخمسين سـيلاب بـا دوره

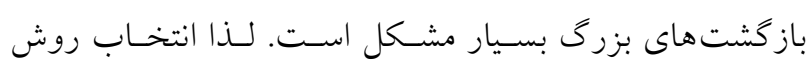

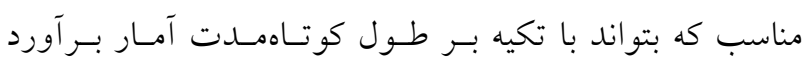

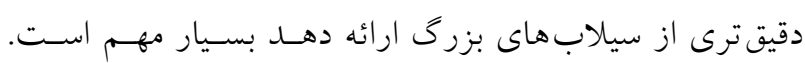

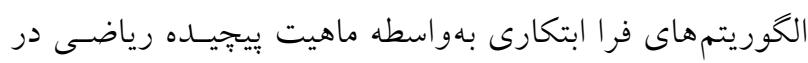

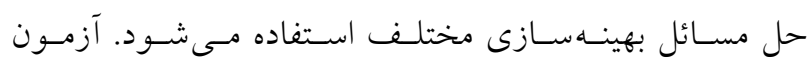
الكوريتمهاى مختلف در تخمـين تِار امترهـاى توابـع توزيـع و

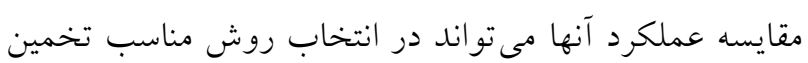

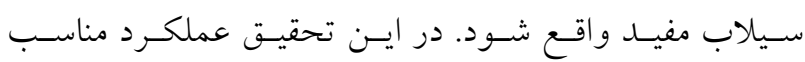




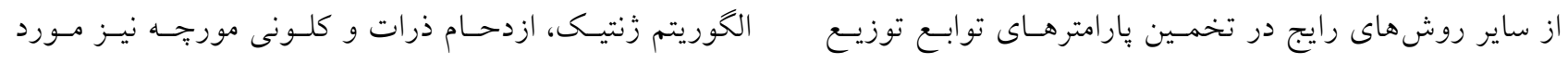

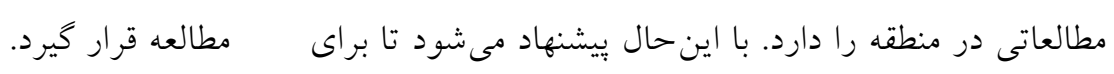

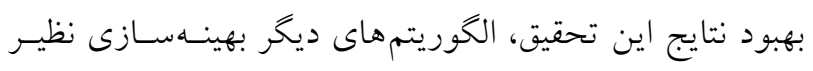

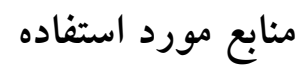

1. Abdolhay, A. 2008. Comparison of hydrological homogenization methods for development of flood regional models. Master thesis, Universiti Putra Malaysia, Serdang, Malaysia.

2. Adamowski, K. 1981. Plotting formula for flood frequency. Journal of the American Water Resources Association 17(2): 197-202.

3. Ahani, A., S. Emamgholizadeh, M. N. Mousavi Nadoushani and K. Azhdari. 2016. Regional flood frequency analysis by hybrid cluster analysis and L-moments. Journal of Watershed Management Research 6(12) 11-20. (In Farsi).

4. Alrashidi, M., S. Rahman and M. Pipattanasomporn. 2020. Metaheuristic optimization algorithms to estimate statistical distribution parameters for characterizing wind speeds. Renewable Energy 149: 664-681.

5. Chavoshi, S., W. N. Azmin Sulaiman, B. Saghafian, M. D. Sulaiman and L. A. Manaf. 2012. Soft and hard clustering methods for delineation of hydrological homogeneous regions in the southern strip of the Caspian Sea watershed. Journal of Flood Risk Management 5 (4): 282-294.

6. Chavoshi, S., W. N. Azmin Sulaiman, B. Saghafian, M. D. Sulaiman and L. A. Manaf. 2013. Flood prediction in southern strip of Caspian Sea watershed. Journal of Water Resources 40(6): 593-605. DOI: 10.1134/S0097807813060122.

7. Farsadnia, F., P. Haghighat Jou, Z. Shamohamadi Heidari and A. R. Moghaddam Nia. 2014. Flood regionalization of Mazandaran Province's watersheds by using Fuzzy Clustering Algorithm. Journal of Iran-Watershed Management Science and Engineering 8(24): 61-65. (In Farsi).

8. Fayaz Bakhsh, H., M. Kavian Poor and M. Hedaiati Zadeh. 2015. The comparison of artificial neural network and linear regression in regional flood modeling. Proceeding of the 10th International Congress on Civil Engineering, Civil Engineering Faculty, Tabriz University.

9. Freitas de Andrade, C., L. Ferreira dos Santos, M. V. Silveira Macedo, P. A. Costa Rocha and F. Ferreira Gomes. 2019. Four heuristic optimization algorithms applied to wind energy: determination of Weibull curve parameters for three Brazilian sites. International Journal of Energy Environment Engineering 10: 1-12.

10. Gelder, P. H. A. J. M. 2003. Statistical estimation methods in hydrological engineering. In: Proceedings of 2003 International Scientific Seminar, Publishing House of the Institute of Geography, Delft University of Technology, Netherlands.

11. Greenwood, J. A., J. M. Landwehr, N. C. Matalas and J. R. Wallis. 1979. Probability weighted moments: definition and relation to parameters of several distributions expressible in inverse form. Water Resources Research 15(5): 1049-1054.

12. Grimaldi S, S. -C. Kao, A. Castellarin, S. -M. Papalexiou, A. Viglione, F. Laio, H. Aksoy and A. Gedikli. 2011. Statistical hydrology. PP. 479-517. In: Peter Wilderer (Eds.), Treatise on Water Science, Oxford: Academic Press.

13. Hassanzadeh, A., A. Abdi, S. Talatahari and V. P. Singh. 2011. Metaheuristic algorithms for hydrologic frequency analysis. Water Resources Management 25(7): 1855-1879.

14. Karaboga, D. 2005. An idea based on honey bee swarm for numerical optimization. Technical Report-TR06, Department of Computer Engineering, Engineering Faculty, Erciyes University.

15. Kazemikia, S., T. Besharati, M. Zolfaghari and M. R. Ghanbarpour. 2016. Comparative study of maximum and partial duration series in flood frequency analysis (Case study in Talar and Babolrud watersheds in Mazandaran Province. Journal of Iran-Watershed Management Science and Engineering 10(3): 113-125. (In Farsi).

16. Langat, P. K., L. Kumar, R. Koech and M. K. Ghosh. 2019. Hydro-morphological characteristics using flow duration curve, Historical data and remote sensing: Effects of land use and climate. Water 11: 309-329.

17. Molina-Aguilar, J. P., A. Gutierrez-Lopez, J. A. Raynal-Villaseñor and L. G. Garcia-Valenzuela. 2019. Optimization of parameters in the generalized extreme-value distribution type 1 for three populations using harmonic search. Atmosphere 10: 257.

18. Rostamin Kamrood, M., Z. Shah Mohamad Heidari, P. Haghighatjoo and A. Moghadamnia. 2011. Regional flood frequency analysis using L-moments methods in Gilan Province' catchments. Journal of Iran Water Resources Engineering 4: 39-50. (In Farsi). 
19. Saghafian, B. and H. Farazjoo. 2007. Flood generation delineating and flooding priority of hydrologic units in Golstan Dam basin. Journal of Iran-Watershed Management Science and Engineering 1(1): 1-11. (In Farsi).

20. Shabanloo, S., H. Sedghi, B. Saghafian and H. Moosavi Jahromi. 2008. Flood mapping in Golestan river network using GIS. Journal of Iran Water Research 2 (3): 11-22. (In Farsi).

21. Sheikh, Z., A. Dehvar and F. Farsadnia. 2014. Comparison of canonical kriging and linear moments methods for regional flood frequency analysis in Mazandaran province. Journal of Iran-Watershed Management Science and Engineering 8(25): 25-38. (In Farsi).

22. Shin, J., J. Heo, C. Jeong and T. Lee. 2014. Meta-heuristic maximum likelihood parameter estimation of the mixture normal distribution for hydro-meteorological variables. Stochastic Environmental Research and Risk Assessment 28: 347-358.

23. Shin, J. -Y., T. Lee and T. B. M. Ouarda. 2015. Heterogeneous mixture distributions for modeling multisource extreme rainfalls. Journal of. Hydrometeorology 16: 2639-2657.

24. Sun, J., J. M. Garibaldi and C. Hodgman. 2012. Parameter estimation using metaheuristics in systems biology: a comprehensive review. Computational Biology and Bioinformatics, IEEE/ACM Transactions on 9(1): 185-202.

25. Yang, X., A. Gandomi, S. Talatahari and A. H. Alavi. 2012. Metaheuristics in Water, Geotechnical and Transport Engineering. Elsevier, Hardcover ISBN 0123983177, 9780123983176.

26. Yoon, Y., Ch. Jeong and T. Lee. 2013. Application of harmony search to design storm estimation from probability distribution models Journal of Applied Mathematics 1-11. Article ID 932943, 11 pages. Available online at: http://dx.doi.org/10.1155/2013/932943. 


\title{
Evaluating the Performance of the Artificial Bee Colony Algorithm in Flood Frequency Analysis
}

\author{
S. Chavoshi* and K. Shirani ${ }^{1}$
}

(Received: September 29-2019; Accepted: May 3-2020)

\begin{abstract}
Selection of the appropriate distribution function and estimation of its parameters are two fundamental steps in the accurate estimation of flood magnitude. This study relied on the concept of optimization by meta heuristic algorithms to improve the results obtained from the conventional methods of parameter estimation, such as maximum likelihood (ML), moments (MOM) and probability weighted moments (PWM) methods. More specifically, this study aimed to improve flood frequency analysis using the Artificial Bee Colony algorithm (ABC). The overall performance of this algorithm was compared to the conventional methods by employing goodness of fit statistics, correlation coefficient (CC), coefficient of efficiency (CE) and root mean square error (RMSE). The study area, Babolrood catchment located in southern bank of Caspian Sea, has been subjected to annual flooding events. A total of 6 hydrometry stations in the study area were delineated and their data were used in the analysis of 6 distribution functions of Normal, Gumbel, Gamma, Pearson Type 3, General Extreme Value and General Logistic. This analysis indicated that Gamma and Pearson Type 3 were the most appropriate distribution functions for flood appraisal in the study area, according to the $\mathrm{ABC}$ and conventional methods, respectively. Also, the results showed that ABC outperformed ML, MOM and PWM; so, Gamma could be recommended as the most reliable distribution function for flood frequency analysis in the study area.
\end{abstract}

Keywords: Flood frequency, Parameter estimation, Metaheuristic algorithm, Artificial bee colony.

1. Soil Conservation and Watershed Management Research Department, Isfahan Agricultural and Natural Resources Research and Education Center, AREEO, Isfahan, Iran.

*: Corresponding author, Email: chsatar@gmail.com 